\title{
Aucubin alleviates oxidative stress and inflammation via Nrf2-mediated signaling activity in experimental traumatic brain injury
}

Han Wang ${ }^{1,2+}$, Xiao-Ming Zhou ${ }^{3 \dagger}$, Ling-Yun Wu ${ }^{1 \dagger}$, Guang-Jie Liu', Wei-Dong Xu ${ }^{2}$, Xiang-Sheng Zhang ${ }^{1}$, Yong-Yue Gao', Tao Tao', Yan Zhou'1, Yue Lu', Juan Wang ${ }^{1}$, Chu-Lei Deng ${ }^{2}$, Zong Zhuang ${ }^{1}$, Chun-Hua Hang ${ }^{1 *}$ and Wei $\mathrm{Li}^{1 *}$ (D)

\begin{abstract}
Background: Aucubin (Au), an iridoid glycoside from natural plants, has antioxidative and anti-inflammatory bioactivities; however, its effects on a traumatic brain injury (TBI) model remain unknown. We explored the potential role of $\mathrm{Au}$ in an $\mathrm{H}_{2} \mathrm{O}_{2}$-induced oxidant damage in primary cortical neurons and weight-drop induced-TBI in a mouse model.

Methods: In vitro experiments, the various concentrations of Au $(50 \mu \mathrm{g} / \mathrm{ml}, 100 \mu \mathrm{g} / \mathrm{ml}$, or $200 \mu \mathrm{g} / \mathrm{ml})$ were added in culture medium at $\mathrm{O}$ h and $6 \mathrm{~h}$ after neurons stimulated by $\mathrm{H}_{2} \mathrm{O}_{2}(100 \mu \mathrm{M})$. After exposed for $12 \mathrm{~h}$, neurons were collected for western blot (WB), immunofluorescence, and M29,79-dichlorodihydrofluorescein diacetate (DCFH-DA) staining. In vivo experiments, Au (20 mg/kg or $40 \mathrm{mg} / \mathrm{kg})$ was administrated intraperitoneally at $30 \mathrm{~min}, 12 \mathrm{~h}, 24 \mathrm{~h}$, and $48 \mathrm{~h}$ after modeling. Brain water content, neurological deficits, and cognitive functions were measured at specific time, respectively. Cortical tissue around focal trauma was collected for WB, TdT-mediated dUTP Nick-End Labeling (TUNEL) staining, Nissl staining, quantitative real time polymerase chain reaction (q-PCR), immunofluorescence/immunohistochemistry, and enzyme linked immunosorbent assay (ELISA) at $72 \mathrm{~h}$ after TBI. RNA interference experiments were performed to determine the effects of nuclear factor erythroid- 2 related factor 2 (Nrf2) on TBI mice with $\mathrm{Au}(40 \mathrm{mg} / \mathrm{kg}$ ) treatment. Mice were intracerebroventricularly administrated with lentivirus at $72 \mathrm{~h}$ before TBI establishment. The cortex was obtained at $72 \mathrm{~h}$ after TBI and used for WB and $\mathrm{q}-\mathrm{PCR}$.

(Continued on next page)
\end{abstract}

\footnotetext{
*Correspondence: hang_neurosurgery@163.com; Iwxzlw@126.com

${ }^{\dagger}$ Han Wang, Xiao-Ming Zhou and Ling-Yun Wu contributed equally to this work.

'Department of Neurosurgery, Nanjing Drum Tower Hospital, The Affiliated Hospital of Nanjing University Medical School, 321\# Zhongshan Road, Nanjing 210008, China

Full list of author information is available at the end of the article
}

(C) The Author(s). 2020 Open Access This article is licensed under a Creative Commons Attribution 4.0 International License, which permits use, sharing, adaptation, distribution and reproduction in any medium or format, as long as you give appropriate credit to the original author(s) and the source, provide a link to the Creative Commons licence, and indicate if changes were made. The images or other third party material in this article are included in the article's Creative Commons licence, unless indicated otherwise in a credit line to the material. If material is not included in the article's Creative Commons licence and your intended use is not permitted by statutory regulation or exceeds the permitted use, you will need to obtain permission directly from the copyright holder. To view a copy of this licence, visit http://creativecommons.org/licenses/by/4.0/ The Creative Commons Public Domain Dedication waiver (http://creativecommons.org/publicdomain/zero/1.0/) applies to the data made available in this article, unless otherwise stated in a credit line to the data. 
(Continued from previous page)

Results: Au enhanced the translocation of Nrf2 into the nucleus, activated antioxidant enzymes, suppressed excessive generation of reactive oxygen species (ROS), and reduced cell apoptosis both in vitro and vivo experiments. In the mice model of TBI, Au markedly attenuated brain edema, histological damages, and improved neurological and cognitive deficits. Au significantly suppressed high mobility group box 1 (HMGB1)-mediated aseptic inflammation. Nrf2 knockdown in TBI mice blunted the antioxidant and anti-inflammatory neuroprotective effects of the Au.

Conclusions: Taken together, our data suggest that Au provides a neuroprotective effect in TBI mice model by inhibiting oxidative stress and inflammatory responses; the mechanisms involve triggering Nrf2-induced antioxidant system.

Keywords: Traumatic brain injury (TBI), Aubucin, Oxidative stress, Inflammation, Nuclear factor erythroid-2 related factor 2 (Nrf2)

\section{Introduction}

Traumatic brain injury (TBI) is a major public health problem in modern society, causing functional impairments and imposing heavy economic burdens to patients. The pathophysiology of TBI consists of primary and secondary brain injuries $[1,2]$. Traumainduced primary brain injury results in tissue damage and neuronal loss. Secondary brain injury occurs hours or days following primary brain injury and involves glutamate excitotoxicity, neuroinflammation, calcium overload, oxidative stress, and cell death [3]. Of these, oxidative stress (OS) and inflammatory reaction are recognized as the important pathobiological features of secondary brain damage $[4,5]$. Excessive production of free radicals leads to lipid peroxidation, protein degradation, and genotoxicity leading to cellular and tissue damage [6]. The brain is an organ with a high content of polyunsaturated fatty acids, which also makes it vulnerable to free radical attack and lipid peroxidation [7]. In addition, OS damage to mitochondrial function can collapse the cellular bioenergetics leading to cell apoptosis [6]. These OSinduced damaged cells release damage associated molecular patterns (DAMPs; e.g., ATP, RNA, highmobility group box 1) to initiate or exacerbate neuroinflammation, which can also further promote ROS generation [8, 9]. Extensive animal data suggest that elevated antioxidant response and reduced inflammation would attenuate brain damage [10-12].

Nuclear factor erythroid-2 related factor 2 (Nrf2) has considerable neuroprotective effects in central nervous system (CNS) diseases [13-15]. Nrf2 is a transcription factor that takes part in regulation of cellular response to oxidative stress. Under normal physiological conditions, Kelch-like ECH-associated protein 1 (Keap1) combines with Nrf2 and enhances Nrf2 degradation. Once stimulated, Nrf2 translocates into the nucleus and binds to the antioxidant response element (ARE) in the promoter of antioxidant genes, thereby inducing the expression of antioxidant and detoxification enzymes and downstream proteins such as heme oxygenase- 1 (HO-1), NAD $(\mathrm{P}) \mathrm{H}$ : quinone oxidoreductase-1 (NQO-1), glutathione peroxidase (GPx), glutathione-S-transferase (GST), and superoxide dismutase (SOD) [16-18].

High-mobility group box 1 (HMGB1) is a member of DAMPs, which instigates and amplifies the noninfectious inflammatory response following TBI [19]. After secretion by inflammatory cells and/or expulsion by damaged neurons into the extracellular milieu [20, 21], HMGB1 interacts with toll-like receptors (TLRs) on the microglia to initiate an immune response that actives myeloid differentiation factor 88 (MyD88) leading to translocation of nuclear factor- $\mathrm{kB}(\mathrm{NF}-\mathrm{kB})$ dimers to the nucleus, where it binds to specific DNA sequences and promotes the transcription of inflammatory cytokine gene [22-24].

Aubucin (1,4a,5,7a-tetrahydro-5-hydroxy-7-hydroxymethylcyclopenta(c)pyran-1-yl-beta-D-glucopyranoside, $\mathrm{Au})$ is a member of the iridoid glycoside family and is widely found in plant species. Several lines of evidence suggest that $\mathrm{Au}$ has a wide range of pharmacological properties including antioxidation, anti-aging, anti-inflammation, anti-fibrosis, anti-tumor, and hepatoprotection [25]. Recently, its anti-inflammatory and antioxidative functions have become a focus of research. Studies have shown that Au provides neuroprotective effects via anti-inflammation and antioxidative properties [26-30]. Nevertheless, its molecular mechanisms are not well understood. Recent reports have found that $\mathrm{Au}$ both exerts antioxidant and anti-inflammation properties by activating the Nrf2 signaling pathway in non-central nervous system diseases [31, 32]. However, to date, it remains unknown as to whether Au has the same protective effects on TBI. Therefore, we investigated the effects of $\mathrm{Au}$ on the secondary brain injury in an experimental mouse TBI model and tried to explore potential molecular mechanisms. 


\section{Materials and methods \\ Animals}

Pregnant C57BL/6 mice at 16-18 days gestation and adult male C57BL/6 mice were purchased from the Animal Center of Drum Tower Hospital, Nanjing, China. All adult male C57BL/6 mice (25-30 g) were raised in a 12-h light/dark cycle environment with free access to food and water.

\section{Experiment design \\ Experiment 1}

Seven pregnant mice and 65 fetuses were used in vitro experiments. The primary cortical neurons were randomly assigned into five groups: Control group, $\mathrm{H}_{2} \mathrm{O}_{2}$ group, $\mathrm{H}_{2} \mathrm{O}_{2}+\mathrm{Au}$ groups $(50 \mu \mathrm{g} / \mathrm{ml}, 100 \mu \mathrm{g} / \mathrm{ml}, 200 \mu \mathrm{g} /$ $\mathrm{ml}$ ) for protein extraction ( $n=3$ for each group). In addition, three groups of neurons: Control group, $\mathrm{H}_{2} \mathrm{O}_{2}$ group, and $\mathrm{H}_{2} \mathrm{O}_{2}+$ group $(200 \mu \mathrm{g} / \mathrm{ml})$ were used for immunofluorescence staining and M29,79-dichlorodihydrofluorescein diacetate (DCFH-DA) staining ( $n=3$ for each group).

\section{Experiment 2}

One hundred twenty mice (130 mice underwent the operation, 120 survived) were used in the experiments. The mice were randomly allocated into four groups: Sham group, TBI group, TBI + Au group $(20 \mathrm{mg} / \mathrm{kg}$ and 40 $\mathrm{mg} / \mathrm{kg}$ ). We performed modified Neurological Severity Scores (mNSS), rotarod test, and Morris Water Maze (MWM) test, respectively ( $n=8$ for each group). The other mice were sacrificed 3 days after trauma to measure brain water content (BWC) ( $n=6$ for each group).

\section{Experiment 3}

Ninety-six mice (107 mice underwent the operation, 96 survived) were randomly assigned to four groups: Sham group, TBI group, TBI + Au group $(20 \mathrm{mg} / \mathrm{kg}$ and 40 $\mathrm{mg} / \mathrm{kg}$ ). All mice in this experiment were sacrificed at 3 days after trauma. Six mice in each group were used for western blot (WB), quantitative real time polymerase chain reaction (q-PCR), and enzyme linked immunosorbent assay (ELISA), respectively $(n=6$ for each group). Brain tissues from the remaining mice were used to make paraffin slices for TdT-mediated dUTP NickEnd Labeling (TUNEL) staining, Nissl staining, immunofluorescence (IF) staining, and immunohistochemistry (IHC) staining ( $n=6$ for each group).

\section{Experiment 4}

First, 48 mice (56 mice underwent the operation, 48 survived) were divided into four groups ( $n=6$, each group): Sham group, TBI group, TBI + negative control (NC) group, and TBI + lentiviral vectors (LV) group and sacrificed at 3 days after TBI for WB and q-PCR to verify the effectiveness of the Nrf2-specific shRNA. Then, 30 mice (35 mice underwent the operation, 30 survived) were randomly assigned to five groups ( $n=6$, each group): Sham group, TBI group, TBI + $\mathrm{Au}(40 \mathrm{mg} / \mathrm{kg})$ group, $\mathrm{TBI}+\mathrm{NC}+\mathrm{Au}(40 \mathrm{mg} / \mathrm{kg})$ group, and $\mathrm{TBI}+\mathrm{Lv}+\mathrm{Au}$ (40 mg/kg) group for WB.

\section{Primary cortical neuron culture}

The skull, blood, and meninges were carefully removed from the fetal mice brain. After cortical tissue digested within $0.25 \%$ trypsin (Gibco, USA) for $5 \mathrm{~min}$ at $37{ }^{\circ} \mathrm{C}$, the suspensions with fetal bovine serum (biological industries, USA) were passed through filters with $22 \mu \mathrm{m}$ mesh size (Millipore, USA) and then were centrifuged at $1500 \mathrm{rpm}$ for $5 \mathrm{~min}$. The supernatant was discarded, and the pellets were resuspended in Dulbecco's Modified Eagle Medium (Gibco, USA). The cells were distributed in poly-D-lysine-coated plates. Four hours later, the medium was replaced with neurobasal medium supplemented with streptomycin, penicillin, HEPES, glutamate, and B27 (Gibco, USA). Half of the neurobasal medium was refreshed every 2 days. After 7-8 days culture, neurons were used in vitro experiments.

\section{In vitro and in vivo model establishment}

For in vitro studies, the primary cortical neurons were incubated with $\mathrm{H}_{2} \mathrm{O}_{2}$ dissolved in neuronal culture medium at a final concentration of $100 \mu \mathrm{M}$ for $12 \mathrm{~h}$ according to published research with minor modification [33]. Then, the neurons were collected for WB, IF staining, and DCFH-DA staining. For in vivo experiments, we used the TBI model induced by weight drop. Mice were anesthetized with intraperitoneal sodium pentobarbital $(40 \mathrm{mg} / \mathrm{kg})$ and then placed onto the platform of the weight-drop apparatus. After disinfection, mice scalps were cut with a longitudinal midline incision to expose the skull. Then, the weight-drop device with a $200 \mathrm{~g}$ was released from a height of $2.5 \mathrm{~cm}$, to cause focal trauma on the hemisphere $1.5 \mathrm{~mm}$ lateral to the midline on the mid-coronal plane. Mice with scalp incisions were sutured and returned to their cages and awaked from anesthesia. Mice in Sham group underwent the same procedures except for the weight drop.

\section{Drug administration}

For in vitro studies, Au (cat\# HY-N0664, MedChemExpress, USA) was dissolved in neuronal culture medium at concentrations of $50 \mu \mathrm{g} / \mathrm{ml}, 100 \mu \mathrm{g} / \mathrm{ml}$, or $200 \mu \mathrm{g} / \mathrm{ml}$. After stimulating cells with $100 \mu \mathrm{M} \mathrm{H} \mathrm{H}_{2} \mathrm{O}_{2}$, the various concentrations of $\mathrm{Au}$ were added immediately and given again at $6 \mathrm{~h}$ after $\mathrm{H}_{2} \mathrm{O}_{2}$ administration. For in vivo studies, Au was dissolved in normal saline to reach final concentrations of $4 \mathrm{mg} / \mathrm{ml}$. The intraperitoneal injection of $\mathrm{Au}(20 \mathrm{mg} / \mathrm{kg}$ or $40 \mathrm{mg} / \mathrm{kg})$ was at $30 \mathrm{~min}, 12 \mathrm{~h}, 24 \mathrm{~h}$, 
and $48 \mathrm{~h}$ after TBI. In the RNA interference experiments, the mice were intraperitoneally injected with $\mathrm{Au}$ $(40 \mathrm{mg} / \mathrm{kg})$ at $30 \mathrm{~min}, 12 \mathrm{~h}, 24 \mathrm{~h}$, and $48 \mathrm{~h}$ after TBI establishment.

\section{Preparation of paraffin-embedded sections}

Anesthetized mice were perfused $0.85 \%$ solution followed by $4 \%$ paraformaldehyde, and the brain tissues were removed. After immersion in $4 \%$ paraformaldehyde for $24 \mathrm{~h}$, the brain tissues were dehydration in $45 \%, 55 \%$, $65 \%, 75 \%, 85 \%, 95 \%$, and $100 \%$ ethanol for $30 \mathrm{~min}$, respectively. Then, the tissues were vitrification in $50 \% \mathrm{xy}$ lene (diluted with 100\% ethanol) for $10 \mathrm{~min}$ and $100 \%$ xylene twice for $40 \mathrm{~min}$. Then, brain tissues were made into paraffin blocks that were cut into $6 \mu \mathrm{m}$ sections. The paraffin sections were dewaxed in $100 \%$ xylene twice for $10 \mathrm{~min}, 100 \%$ ethanol twice for $10 \mathrm{~min}$, $95 \%$ ethanol for $5 \mathrm{~min}$, $85 \%$ ethanol for $5 \mathrm{~min}$, and $70 \%$ ethanol for $5 \mathrm{~min}$, respectively. After washing two times with distilled water for $10 \mathrm{~min}$, the slices were boiled in a microwave with citrate buffer solution (cat\# P0083, Beyotime, China) for $15 \mathrm{~min}$ to retrieve antigens and then were used for IF staining, Nissl staining, TUNEL staining, and IHC staining.

\section{WB analysis}

The neurons and brain tissue (Additional file 1: Figure S1) were collected for WB analysis. The procedure of nuclear and total protein extraction was according to manufacturer's instructions. Equal protein amounts were separated using polyacrylamide gel electrophoresis and transferred to polyvinylidene difluoride membranes blocked in 5\% skim milk for $2 \mathrm{~h}$ at indoor temperature. Then, the membranes were incubated with primary antibodies against Nrf2 (1:1000, cat\# ab137550, Abcam), Histone H3 (H3) (1:5000, cat\# AF0009, Beyotime, China), NQO-1 (1:1000, cat\# ab34173, Abcam), HO-1 (1:1000, cat\# ab13248, Abcam), B-cell lymphoma-2 (Bcl2) (1:200, cat\# 196495, Abcam), Bcl-2 Associated X Protein (Bax) (1:200, cat\# ab32503, Abcam), cleavedcaspase 3 (CC3) (1:1000, cat\# 9664, Cell Signaling), matrix metalloprotein-9 (MMP-9) (1:1000, cat\# PB10008, Boster), glutathione peroxidase 1 (GPx1) (1: 1000, cat\# ab22604, Abcam), superoxide dismutase 1 (SOD1) (1:200, cat\# sc-101523, Santa Cruz), Iba-1 (1: 1000, cat\# ab178846, Abcam), HMGB1 (1:100, cat\# sc56698, Santa Cruz), TLR4 (1:200, cat\# sc-30002, Santa Cruz), MyD88 (1:200, cat\# sc-74532, Santa Cruz), NF-кB p65 (1:1000, cat\# 8242, Cell Signaling), inducible Nitric Oxide Synthase (iNOS) (1:1000, cat\# 13120, Cell Signaling), Cyclooxygenase-2 (COX2) (1:500, cat\# sc-19999, Santa Cruz), Interleukin-1 $\beta$ (IL-1 $\beta)$ (1:500, cat\# 12242, Cell Signaling), or $\beta$-actin (1:3000, cat\# BS6007M, Bioword) overnight at $4{ }^{\circ} \mathrm{C}$. After washing 3 times for 15 min with Tris-buffered saline with Tween 20, the membranes were incubated with corresponding HRP conjugated secondary antibodies (1:5000, Bioword) for $1 \mathrm{~h}$ at room temperature. The protein bands were detected using enhanced chemiluminescence (ECL). The ImageJ software was used to measure the optical density of protein bands.

\section{IF staining}

The brain sections with antigen retrieval or cultured cells were treated with QuickBlock ${ }^{\mathrm{Tm}}$ Blocking Buffer (cat\# P0260, Beyotime, China) for $30 \mathrm{~min}$ at room temperature and then incubated with primary antibodies against Nrf2 (1:100, cat\# ab137550, Abcam), MAP2 (1: 200, cat\# sc-32791, Santa Cruz), NeuN (1:200, cat\# MAB377, EMD Millipore), and Iba-1 (1:100, cat\# ab178846, Abcam) overnight at $4{ }^{\circ} \mathrm{C}$. The cells or slides were incubated with corresponding secondary antibodies Alexa Fluor 594 and/or Alexa Fluor 488 (1:200, Jackson ImmunoResearch Incorporation, West Grove, PA, USA). Then, the cells or slides were washed in phosphate buffered saline-Tween twice for $20 \mathrm{~min}$ and counterstained with 4,6-diamidino-2-phenylindole (DAPI) (1:2000, cat\# ab104139, Abcam) for $5 \mathrm{~min}$. Fluorescence was captured on a Zeiss HB050 inverted microscope system. The ImageJ software was used to measure the inflorescence intensity.

\section{DCFH-DA staining}

The procedures of ROS measurement were according to manufacturer's instructions. After stimulating with $\mathrm{H}_{2} \mathrm{O}_{2}$ for $12 \mathrm{~h}$, the neurons were incubated with DCFH-DA (cat\# S0033, Beyotime, China) for $10 \mathrm{~min}$ at $37^{\circ} \mathrm{C}$. Following three washes with serum-free medium (Gibco, USA) for $1 \mathrm{~min}$, the cells were immediately photographed under an inverted fluorescence microscope. The mean fluorescence intensity was analyzed using the ImageJ software.

\section{IHC staining}

After antigens retrieval, the sections were treated with $3 \% \mathrm{H}_{2} \mathrm{O}_{2}$ for $15 \mathrm{~min}$ and QuickBlock ${ }^{\mathrm{mm}}$ Blocking Buffer (cat\# P0260, Beyotime, China) for $30 \mathrm{~min}$ at room temperature. Then, sections were incubated with primary antibodies against HO-1 (1:200 cat\# ab13248, Abcam), NQO1 (1:200, cat\# ab34173, Abcam), and 8hydroxyguanosine (8-OHdG) (1:200, cat\# sc-393871, Santa Cruz) overnight at $4{ }^{\circ} \mathrm{C}$. The slides were washed twice with phosphate-buffered saline (PBS) and incubated with biotinylated secondary antibody (1:500, Vector, Burlingame, CA, USA) and horseradish peroxidase (HRP)-streptavidin reagent (Vector, USA). Then, the sections were re-stained with hematoxylin, and we measured immunoreactivity using 3,3-diaminobenzidine 
(DAB, Zsgb-bio, China). Images were pictured by a microscope. The ImageJ software was used to analyze the IHC images.

\section{Brain water content}

The brain water content was performed at 3 days after TBI. The entire brain was divided into injured hemispheres, cerebellum, and brainstem. Each part was weighed immediately to obtain the wet weight. Brain tissue was dried at $80{ }^{\circ} \mathrm{C}$ for $72 \mathrm{~h}$ and re-weighed again to calculate dry weight. The brain water content was calculated as [(wet weight - dry weight)/wet weight] $\times 100 \%$.

\section{Neurologic function testing}

The mice were assessed using mNSS test on days 1 and 3 after TBI according to previous studies [34]. The mNSS consists of motor (muscle status and abnormal movement), sensory (visual, tactile, and proprioceptive), reflex, and balance tests. One score is awarded for the inability to perform the test or for the lack of a tested reflex. The higher score represents the more serious neurological impairment (normal score, 0; maximal score, 18). Detailed score criteria was shown in Additional file 1: Figure S2.

\section{MWM test}

On the 24th day after the trauma, the mice were performed the MWM test with minor modifications to assess their cognitive functions. Visual cues of figures were hung on the wall of the tank. During the acquisition phase, the mice were continuously trained for 5 days, with 3 trials per day. In each trial, mice were given 1 min to find a submerged platform $1 \mathrm{~cm}$ below the surface of the water. When arrival to the platform, mice were allowed to stay on the platform for $15 \mathrm{~s}$. If failed, mice were guided to the platform and stay for $30 \mathrm{~s}$. The mice were subjected to the probe trials on next day after 5 consecutive training. The platform was removed from the tank, and then, mice were placed in the quadrant opposite the platform to seek platform for $1 \mathrm{~min}$. The ANY-Maze video tracking system was used to videotape the whole process and data.

\section{Rotarod test}

Mice were received 3 days of rotarod test training before TBI induction and then placed in a neutral position on an accelerating rotating rod (from 5 to $40 \mathrm{r} / \mathrm{min}$ within $5 \mathrm{~min}$ ). The blinded experimenters recorded the latency to fall of each mouse. An average latency of three trials in 1 day represented the mouse motor performance. The test was performed before TBI and $0,3,7$, and 14 days following TBI.

\section{TUNEL staining and Nissl staining}

Antigen-repaired brain sections were incubated with TUNEL reaction mixture (cat\# C1089, Beyotime, China) for $1 \mathrm{~h}$ at room temperature. After two washes with PBS for $20 \mathrm{~min}$, the slides were incubated with DAPI for 5 min. Then, the brain sections were washed twice again and exposed under an inverted fluorescence microscope. The TUNEL-positive cells were counted by the ImageJ software. The number of apoptosis cells to DAPI was regarded as an apoptosis index (apoptosis cells/DAPI). For Nissl staining, the sections were stained in Nissl staining solution (cat\# C0117, Beyotime, China) for 5 min, washed with double-distilled water, and mounted with Permount. The pictures were captured under a light microscope. The neurons with visible nuclear and relatively complete cellular morphology were counted by the ImageJ software.

\section{Contents of malondialdehyde (MDA), SOD, ROS, GSH, and GSH-Px measurements}

Levels of MDA, SOD, ROS, GSH, and GSH-Px in serum and brain tissue were measured using ELISA kits (Nanjing Jiancheng Bioengineering Institute, Nanjing, China) according to the manufacturer's instructions at 3 days after TBI.

\section{RNA interference}

The transfection of LV expressing Nrf2-specific shRNA or negative control shRNA for mice in vivo was conducted 3 days prior to TBI modeling. After intraperitoneal anesthesia with sodium pentobarbital $(40 \mathrm{mg} / \mathrm{kg})$, mice with scalp incisions were placed in a stereotaxic device; then, a cranial burr hole $(2.5 \mathrm{~mm}$ in depth, 1.2 $\mathrm{mm}$ lateral from midline, and $0.4 \mathrm{~mm}$ posterior from the bregma) was drilled. The mice underwent injection with $4 \mu \mathrm{L}$ lentiviruses into the lateral ventricles $(2 \mu \mathrm{L} / \mathrm{min})$. The needle remained in place for $30 \mathrm{~s}$ after completing the infusion, and the scalp incision was sutured. The mice in Sham, TBI, and TBI + Au groups received a cranial burr hole but not intracerebroventricular (ICV) injection. The experimental TBI was established 3 days after ICV injection. The Nrf2 shRNA sequence was $5^{\prime}$ AAGCCTTACTCTCCCAGTGAATCGAAATTC ACTGGGAGAGTAAGGCTT-3' and a non-targeting RNA sequence serving as a negative control [35].

\section{Quantitative real-time PCR}

Q-PCR was performed as previously described [36]. Total mRNA was isolated from tissues (Additional file 1: Figure S1) using the Trizol reagent (TAKARA, Japan) and measured using spectrophotometric analysis (OD260/OD280). After reverse transcription of total mRNA into cDNA, qPCR analysis was performed with SYBR Green qPCR Master Mix. Nrf2 forward and reverse primers were $5^{\prime}$ - 
CTACTCCCAGGTTGCCCACA-3' and 5'-CGACTC ATGGTCATCTACAAATGG-3', respectively; HO-1 forward and reverse primers were 5 '-GCTGGTGATGGCTT CCTTGTA-3' and 5' ${ }^{\prime}$-ACCTCGTGGAGACGCTTT ACAT-3', respectively; NQO-1 forward and reverse primers were 5'-ACGACAACGGTCCTTTCCAGA-3' and 5'-CAGAAACGCAGGATGCCACT-3', respectively; $\beta$-actin forward and reverse primers were $5^{\prime}$-GACAGG ATGCAGAAGGAGATTACT-3' and 5'TGATCCACATCTGCTGGAAGGT-3', respectively. All samples were analyzed in triplicate with normalization to the $\beta$ actin in the Sham group. Relative quantification of mRNA expression was measured using the $2^{-\Delta \Delta C T}$ method.

\section{Statistical analysis}

The data were expressed as mean \pm standard deviation (SD) and analyzed using an analysis of variance (ANOVA) followed by Tukey's (one-way) or Bonferroni's (two-way) multiple comparisons post hoc test. Values of $P<0.05$ were considered statistically significant. Analyses were performed using the SPSS version 20.0 software.

\section{Results}

Effects of Au on $\mathrm{H}_{2} \mathrm{O}_{2}$-induced primary cortical neurons

To determine the antioxidative effects of $\mathrm{Au}$, we used $\mathrm{H}_{2} \mathrm{O}_{2}$ to stimulate primary neurons to construct a vitro model of oxidative stress. Western blot analysis showed that $\mathrm{Au}(50 \mu \mathrm{g} / \mathrm{ml}, 100 \mu \mathrm{g} / \mathrm{ml}$, and $200 \mu \mathrm{g} / \mathrm{ml})$ treatment significantly enhanced the cytoplasmic Nrf2 translocation to the nucleus and increased the expression of NQO-1, HO-1, and Bcl2 in a dose-dependent manner (Fig. 1a, b). In addition, western blot analysis also showed that $\mathrm{Au}$ reduced the expression of $\mathrm{Bax}$ and $\mathrm{CC} 3$ in neurons after $\mathrm{H}_{2} \mathrm{O}_{2}$ stimulation. As shown in Fig. $1 \mathrm{c}$ and $d, \mathrm{H}_{2} \mathrm{O}_{2}$ significantly increased ROS levels when compared with those of the Control group, and this effect was reversed by $\mathrm{Au}(200 \mu \mathrm{g} / \mathrm{ml})$ treatment. Immunofluorescence staining was consistent with the western blot results that $\mathrm{Au}$ promoted the cytoplasmic Nrf2 into the nucleus in conditions of oxidative damage (Fig. 1e).

\section{Au ameliorated brain edema and improved short-term neurologic functions after TBI}

At 3 days after TBI, BWC increased significantly. Au (20 $\mathrm{mg} / \mathrm{kg}$ or $40 \mathrm{mg} / \mathrm{kg}$ ) treatment alleviated brain edema (Fig. 2a). As shown in Fig. 2c, d, TBI caused the increased expression of the MMP-9 protein, which destroys the blood-brain barrier. However, this effect was reversed by $\mathrm{Au}(20 \mathrm{mg} / \mathrm{kg}$ or $40 \mathrm{mg} / \mathrm{kg})$ treatment. To further explore the neuroprotective effects of $\mathrm{Au}$ on TBI, we measured neurologic functions in the mice. Although Au therapy on the first day of trauma did not improve mNSS scores, it did improve significantly after 3 days of treatment (Fig. 2b). Furthermore, significantly greater recovery was observed in Au-treated TBI mice than in TBI mice as measured using the rotarod test (Fig. 2e).

\section{Au improved long-term neurologic functions after TBI}

During the training days (Fig. 2j) or the probe trials (Fig. $2 k$ ), there was no difference in average swimming speed among the four groups. However, TBI significantly caused the mice to show prolonged escape latency in the cued learning phase. By contrast, mice in TBI + Au groups had a shortened escape latency compared with those in the TBI group, suggesting that Au improved the learning functions in TBI mice (Fig. 2i). In the probe trial period, the TBI mice treated with Au had significantly greater correct quadrant dwell time (Fig. 2l) and more platform crossings (Fig. 2f, m) than did TBI mice, suggesting that $\mathrm{Au}$ improved memory functions in TBI mice.

\section{Au promoted neurons survival after TBI}

In the vivo studies, we also measured the expression of apoptosis-associated proteins, and western blot results were consistent with those in vitro experiments. $\mathrm{Au}(20 \mathrm{mg} / \mathrm{kg}$ or $40 \mathrm{mg} / \mathrm{kg})$ treated-TBI mice had significantly elevated expression of $\mathrm{Bcl} 2$ and lower expression of Bax and CC3 than those of TBI mice (Fig. 3a, b). TUNEL staining showed that there were significantly more apoptotic positive cells in the TBI group than in TBI + Au groups (Fig. 3c, e). Then, we measured damaged neurons in the ipsilateral cortex surrounding the injury site. As shown in Fig. 3d, the neurons were clear and intact in the Sham group. By contrast, damaged neurons displayed irregular cell bodies, shrinkage, and hyperchromatic nuclei in significantly greater numbers in the TBI group. After $\mathrm{Au}$ administration, less neuron loss was found than in the TBI group (Fig. 3f). Meanwhile, we explored the effects of $\mathrm{Au}$ on neurons in the $\mathrm{CA} 1$ region of the hippocampus. TBI mice with $\mathrm{Au}$ $(20 \mathrm{mg} / \mathrm{kg}$ or $40 \mathrm{mg} / \mathrm{kg})$ administration had less apoptotic positive cells and neuronal loss (Additional file 1: Figure S3).

\section{Au attenuated oxidative stress after TBI}

SOD, MDA, GSH, and GSH-Px levels in serum and brain tissue were measured to determine whether $\mathrm{Au}$ suppressed TBI-induced oxidative damage. Both in serum and brain tissue, TBI significantly decreased SOD, GSH, and GSH-Px levels, whereas increased MDA levels. After Au application, mice in the TBI + $\mathrm{Au}$ groups $(20 \mathrm{mg} / \mathrm{kg}$ or $40 \mathrm{mg} / \mathrm{kg})$ displayed significantly higher serum levels and brain concentrations 


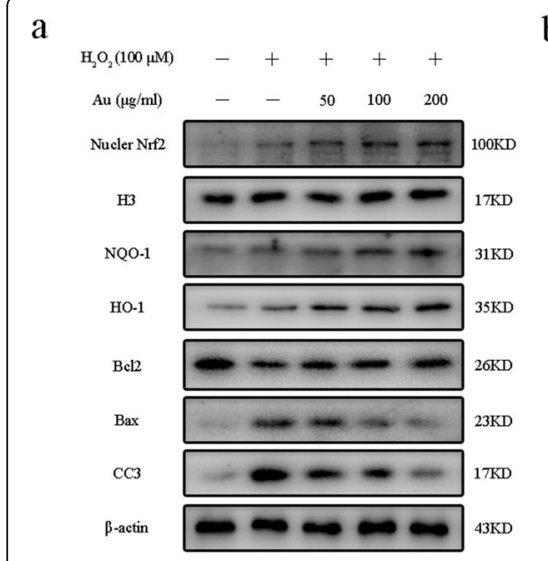

$\mathrm{C}$
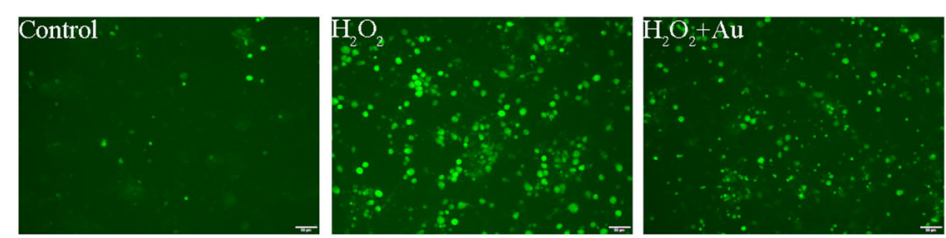

e
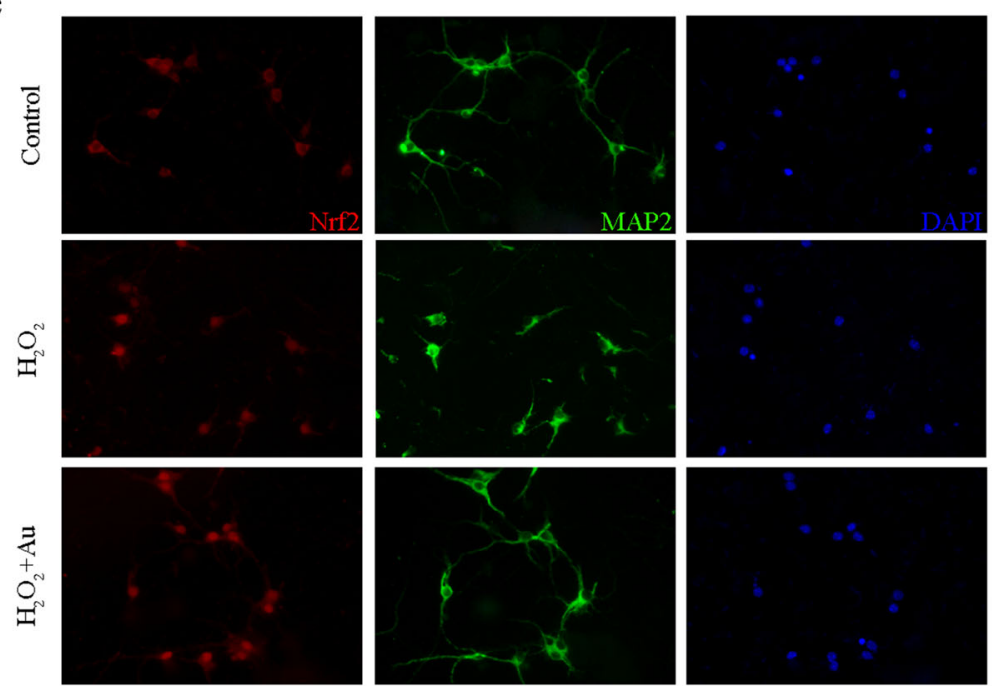

Fig. 1 Effects of Au on the primary neurons exposed to $100 \mu \mathrm{M} \mathrm{H}_{2} \mathrm{O}_{2}$. $\mathbf{a}$, b Representative western blot bands (a) and quantification of relative protein expression (b) for nuclear Nrf2, NQO-1, HO-1, Bcl2, Bax, and CC3. c, d Representative micrographs (c) and quantification (d) of DCFH-DA staining of Control group, $\mathrm{H}_{2} \mathrm{O}_{2}$ group, and $\mathrm{H}_{2} \mathrm{O}_{2}+\mathrm{Au}(200 \mathrm{\mu g} / \mathrm{ml})$ group in primary neurons. e Representative image of immunofluorescence staining of Control group, $\mathrm{H}_{2} \mathrm{O}_{2}$ group, and $\mathrm{H}_{2} \mathrm{O}_{2}+\mathrm{Au}(200 \mu \mathrm{g} / \mathrm{ml})$ group. Bars represent the mean $\pm \mathrm{SD}$. ${ }^{\#} P<0.05$ versus Control group; ${ }^{*} P<$ 0.05 versus $\mathrm{H}_{2} \mathrm{O}_{2}$ group. Scale bars $=50 \mu \mathrm{m}$ ( $n=3$ for each group)

of SOD, GSH, and GSH-Px than did TBI mice. Furthermore, mice with $\mathrm{Au}$ injection had significantly lower concentrations of serum and brain MDA than did those in the TBI group (Fig. 4a-d). Similarly, western blot results showed that the protein expression of SOD1 and GPx1 significantly increased in the $\mathrm{TBI}+\mathrm{Au}$ groups as compared with those of the TBI group (Fig. $4 \mathrm{e}-\mathrm{g}$ ). In Fig. 4i, j, IHC staining was performed to determine whether $\mathrm{Au}$ treatment inhibited the production of the oxidative stress marker 8-
OHdG. We found that Au-treated mice had significantly fewer $8-\mathrm{OHdG}{ }^{+}$cells than did TBI mice.

\section{Au promoted the expression and nuclear translocation of} Nrf2 after TBI

WB analyses suggested that TBI significantly increased total and nuclear Nrf2 expression compared with that of the Sham group. TBI mice with Au treatment had further increased expression of total and nuclear Nrf2 (Fig. 5a, b, d). Meanwhile, cytoplasmic 


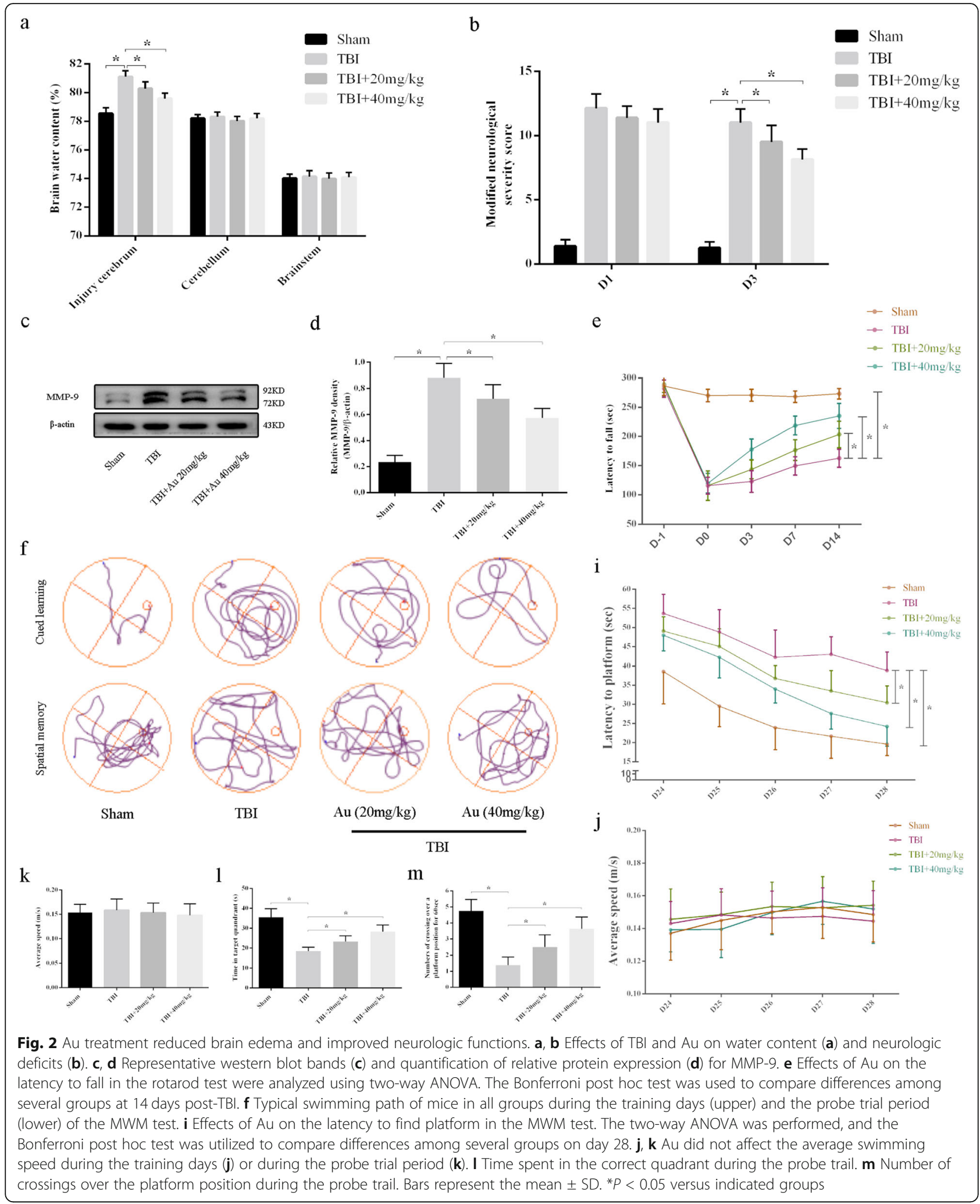

Nrf2 protein levels in TBI $+\mathrm{Au}$ groups were significantly lower than those of the TBI group (Fig. 5a, c). Immunofluorescence staining confirmed our WB findings that $\mathrm{Au}$ treatment increased protein levels of total Nrf2 and enhanced Nrf2 nuclear translocation in neurons (Fig. 5e and Additional file 1: Figure S4). 
a

C
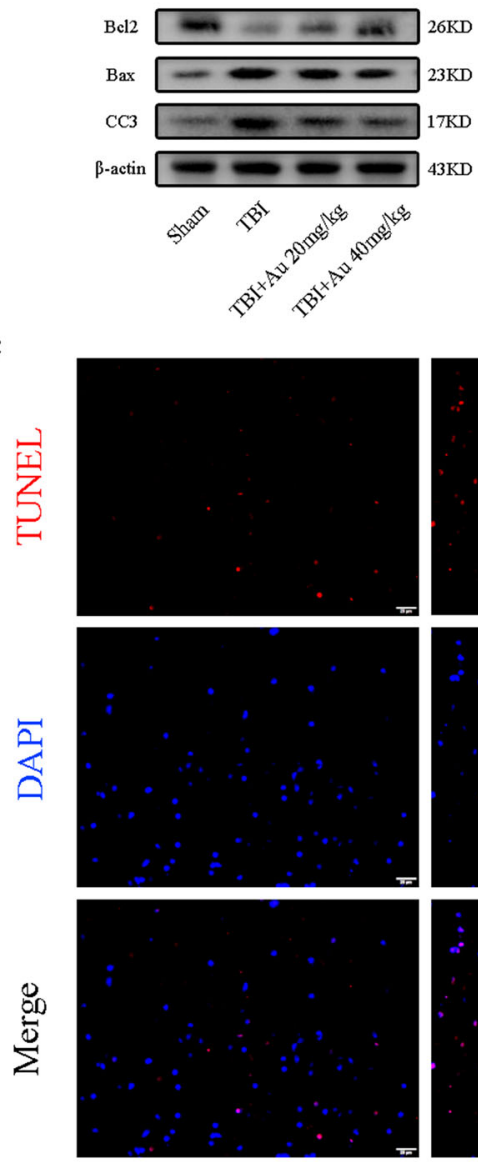

Sham

d

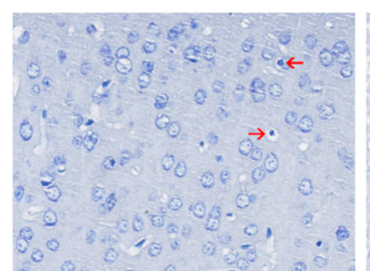

Sham

e

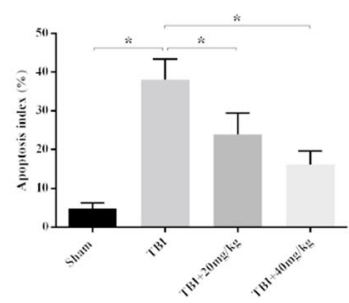

b
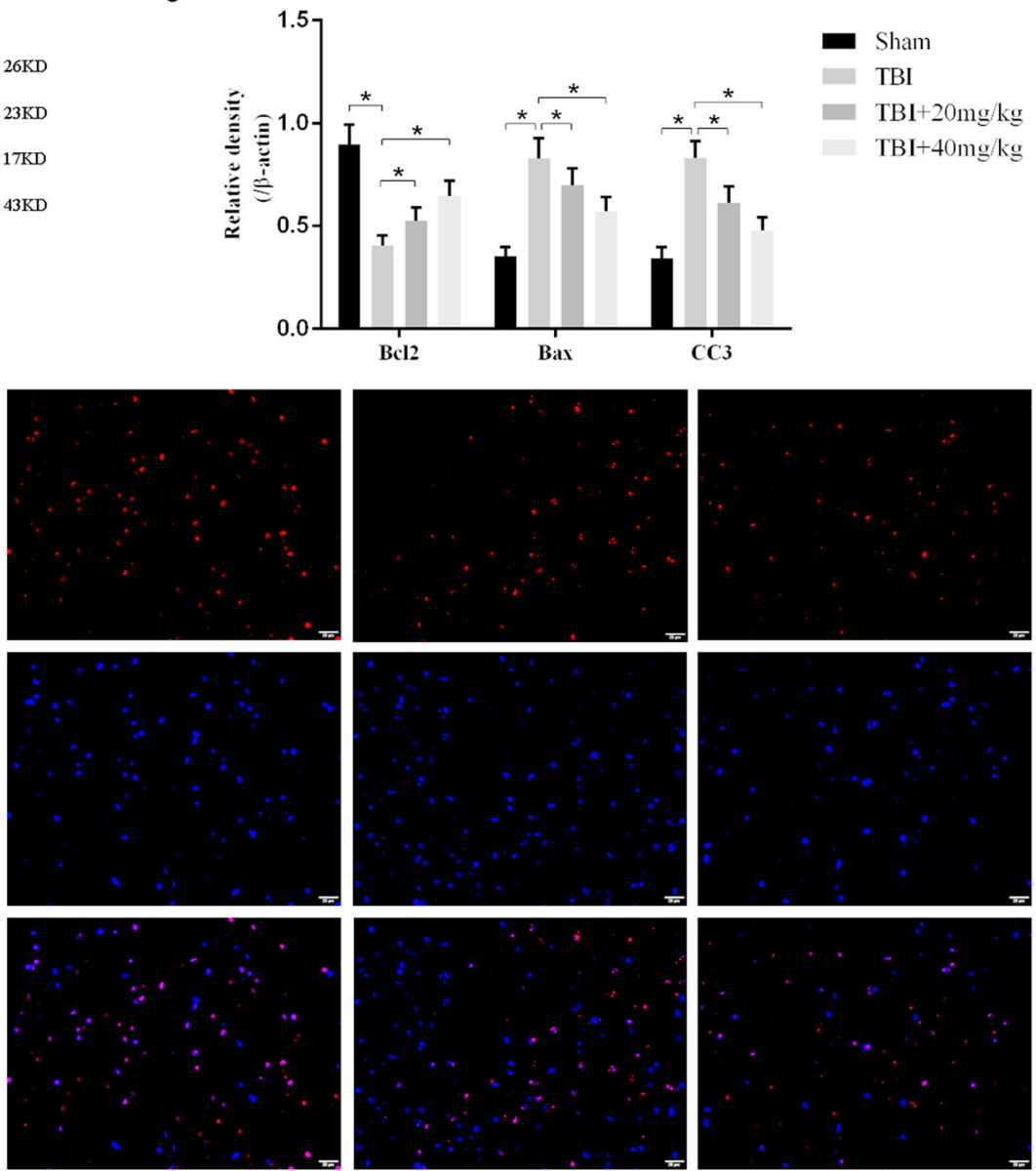

TBI
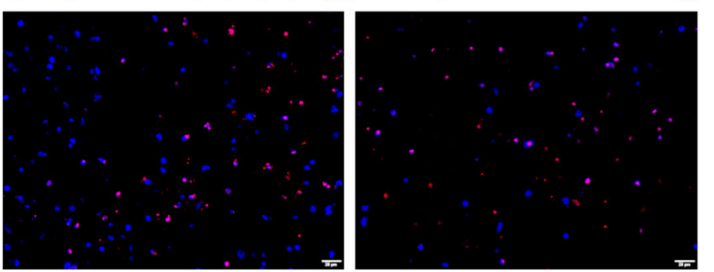

$\mathrm{Au}(20 \mathrm{mg} / \mathrm{kg})$

$\mathrm{Au}(40 \mathrm{mg} / \mathrm{kg})$

TBI

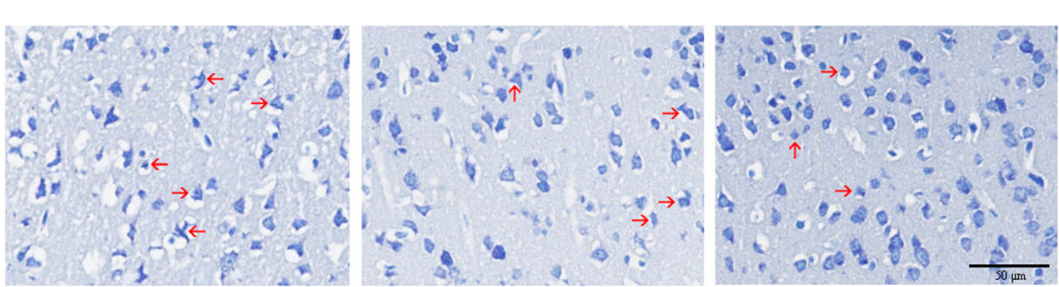

TBI

$\mathrm{Au}(20 \mathrm{mg} / \mathrm{kg})$ $\mathrm{Au}(40 \mathrm{mg} / \mathrm{kg})$

TBI

g
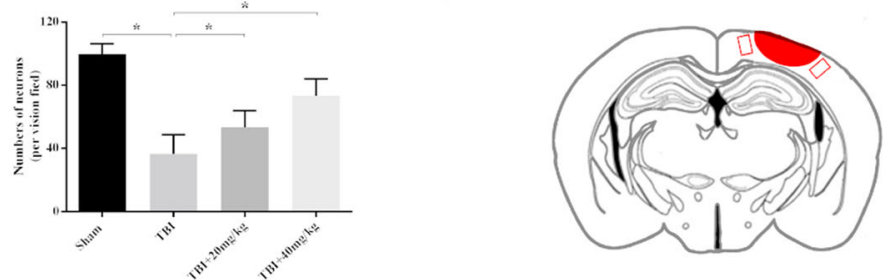

Fig. 3 (See legend on next page.) 
(See figure on previous page.)

Fig. 3 Au decreased the neural apoptosis and neuronal loss caused by TBI. $\mathbf{a}, \mathbf{b}$ Representative WB bands (a) and quantification of relative protein expression (b) for Bcl2, Bax, and CC3. c-f Representative photomicrographs and quantification of TUNEL staining (c, e Scale bars = $20 \mu \mathrm{m})$ and Nissl staining $(\mathbf{d}, \mathbf{f}$ Scale bars $=50 \mu \mathrm{m})$ in cortex of the traumatized side. The red arrow indicated damaged neurons. $\mathbf{g}$ Diagram of mouse brain section showing the location of lesion cavity (red area) and photograph region (red squares). Bars represent the mean \pm SD. ${ }^{*} P<0.05$ versus indicated groups ( $n=6$ for each group)

\section{Au upregulated the expression of Nrf2 downstream proteins}

We measured downstream pathway expression of Nrf2 at the mRNA and protein levels. Q-PCR results showed that TBI increased both HO-1 and NQO-1 mRNA expression, and $\mathrm{Au}$ further distinctly enhanced their expression in a dose-dependent manner (Fig. 6a, b). Consistent with mRNA variations, WB results demonstrated that $\mathrm{Au}$ caused greater protein expression of $\mathrm{HO}-1$ and NQO-1 than in the TBI group (Fig. 6c, d). These results

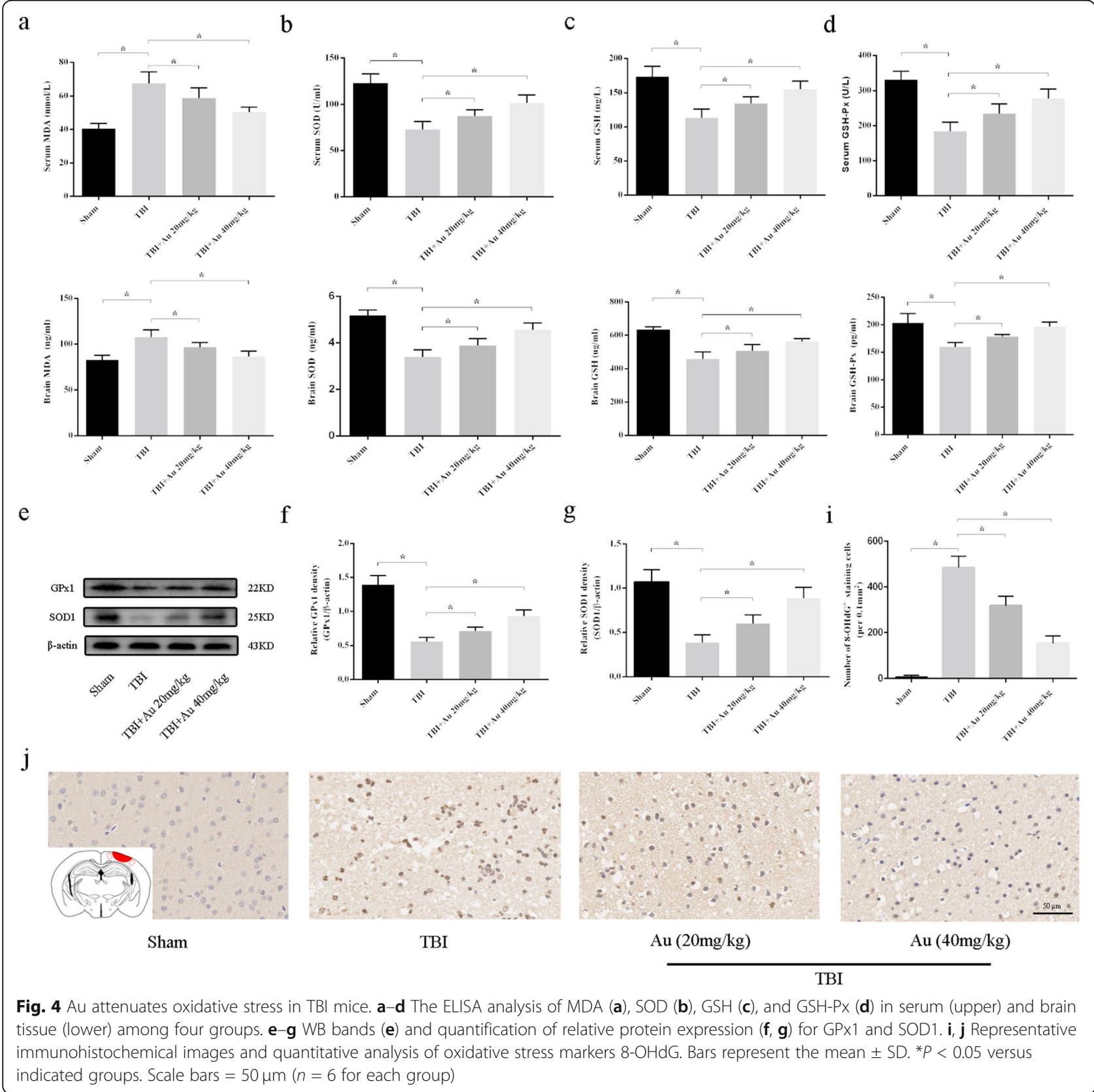




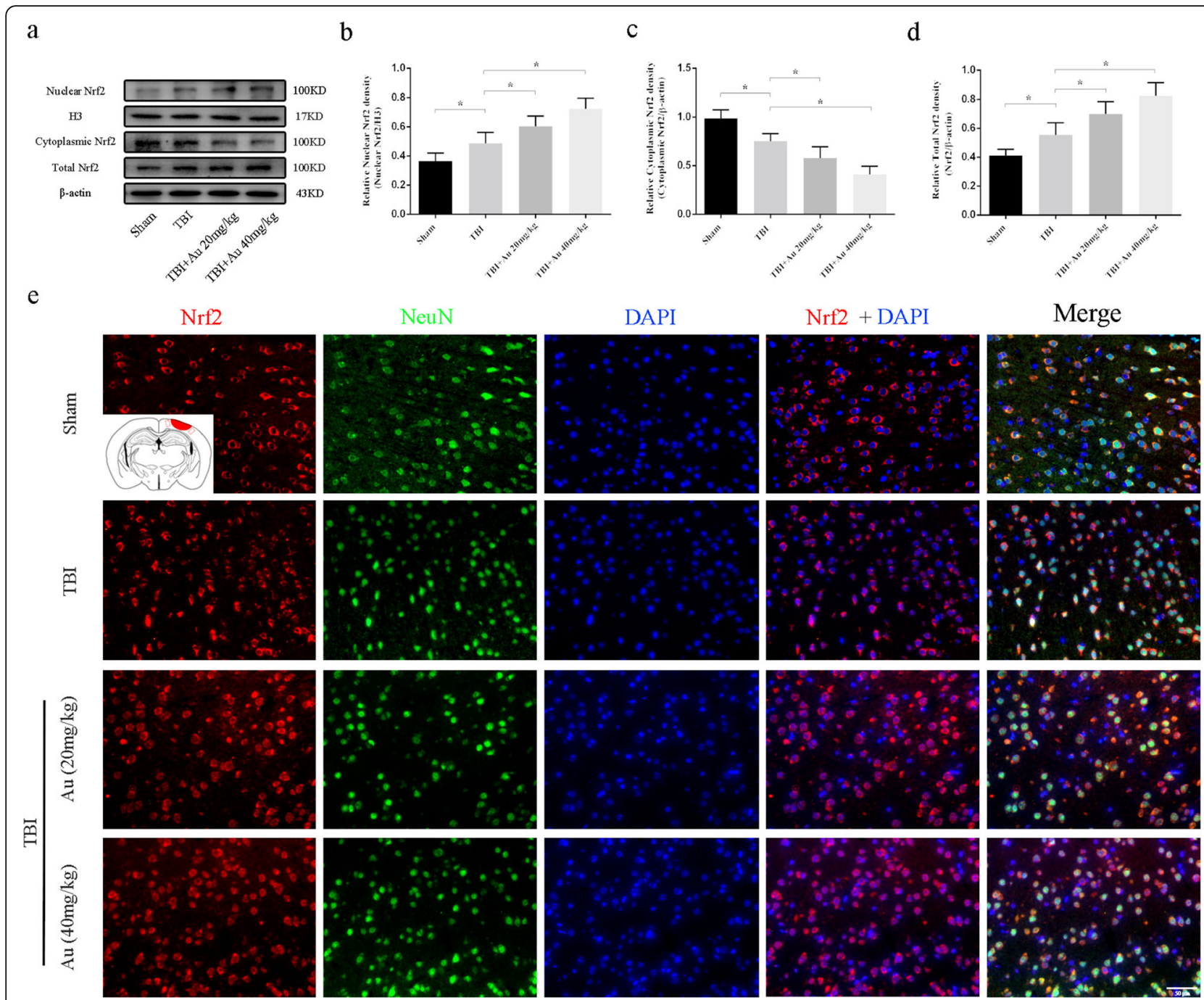

Fig. 5 Effects of Au on protein level of Nrf2 in the perilesional cortex after TBI. a-d Representative WB bands (a) and quantification analysis of nuclear Nrf2 (b), cytoplasmic Nrf2 (c), and total Nrf2 (d). e Typical double immunofluorescence images of NeuN and Nrf2 (scale bars = $50 \mu m$ ). Bars represent the mean $\pm \mathrm{SD}$. ${ }^{*} P<0.05$ versus indicated groups ( $n=6$ for each group)

indicated that $\mathrm{Au}$ induced the expression of $\mathrm{HO}-1$ and NQO-1 at the transcriptional and translational levels. In addition, representative immunohistochemical images of HO-1 and NQO-1 proteins are shown in Fig. 6e.

\section{Au suppressed inflammatory response in the perilesional cortex after TBI}

To measure microglial recruitment in the perilesional cortex, we used WB analyses and IF staining. As shown in Fig. $7 \mathrm{a}$ and $\mathrm{b}$, the number of microglia in the TBI $+\mathrm{Au}$ groups markedly reduced compared with that of TBI group. In addition, WB analysis showed that Au significantly weakened the increased expression levels of Iba- 1 in the injured tissue (Fig. $7 \mathrm{c}, \mathrm{d}$ ). These results suggested that $\mathrm{Au}$ could inhibit microglial aggregation caused by TBI. Microglial activation is accompanied by morphological changes.
Microglia from the TBI mice showed enlarged, round cell bodies, and shortened processes, while those in TBI + Au groups exhibited a less-activated phenotype with smaller cell bodies and elongated processes (Fig. 7a).

Then, we detected the expression of HMGB1 and downstream proteins. Au-treated mice had lower levels of HMGB1, TLR4, MyD88, and total NF-kB p65 than did TBI mice (Fig. 8a-c). Furthermore, NF-kB p65 in the nucleus was reduced in the TBI + Au group (Fig. 8a, c). There were consistent changes in inflammatory cytokines (Fig. 8d, e).

Nrf2 interference weakened the antioxidant and antiinflammatory effects of Au on TBI

We wondered whether the neuroprotective effect of $\mathrm{Au}$ depended on Nrf2 activation after TBI. We applied Au $(40 \mathrm{mg} / \mathrm{kg}$ ) together with Nrf2 shRNA co-treatment. To 
a

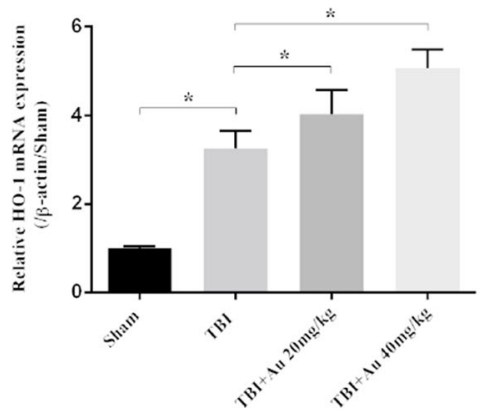

c
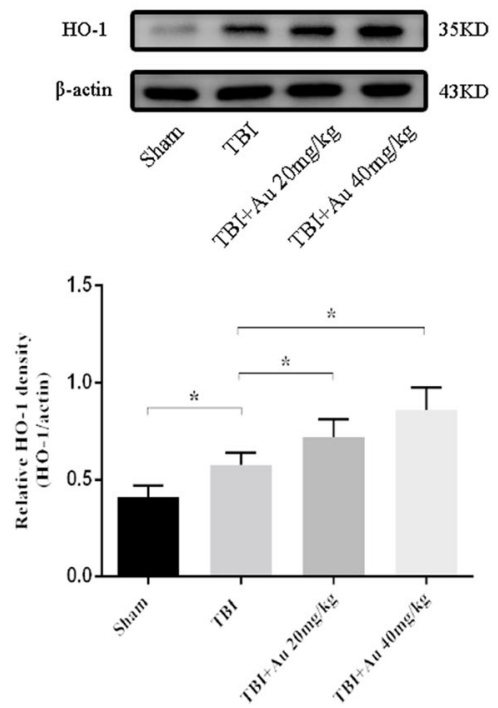

b

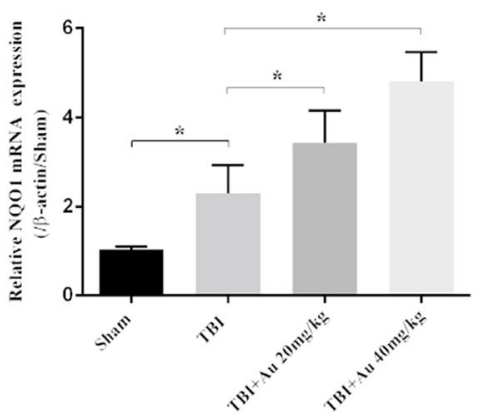

d
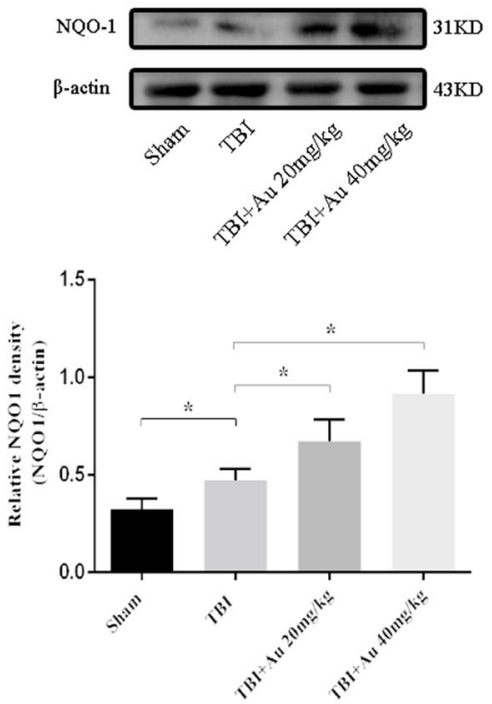

e
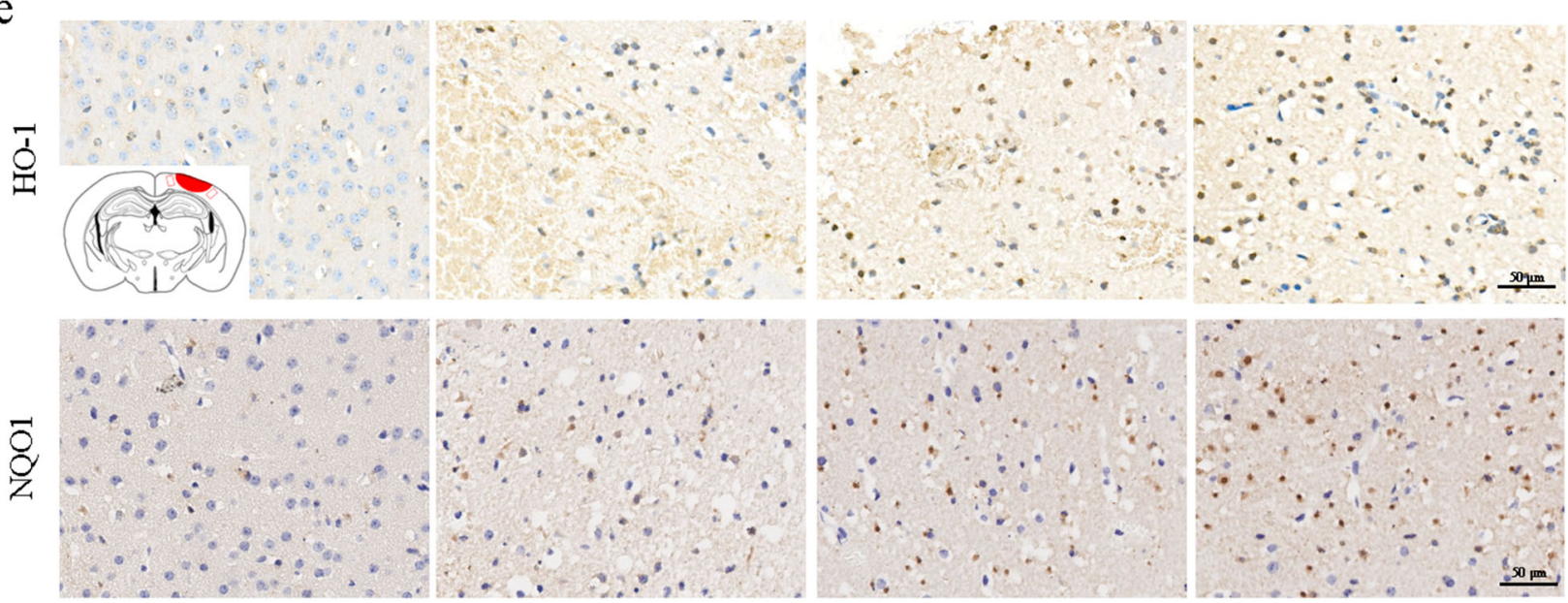

Sham

TBI

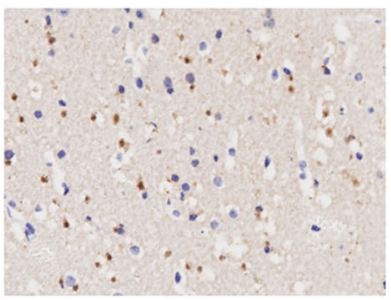

$\mathrm{Au}(20 \mathrm{mg} / \mathrm{kg})$

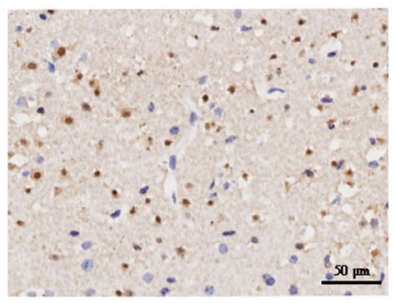

$\mathrm{Au}(40 \mathrm{mg} / \mathrm{kg})$

TBI

Fig. 6 Au upregulated the expression of HO-1 and NQO-1. a, b The mRNA levels of HO-1 (a) and NQO-1 (b) in cerebral cortex of the injured side. c, $\mathbf{d}$ WB bands (top) and quantitative analysis (bottom) of HO-1 (c) and NQO1 (d). e Representative IHC images of HO-1 (upper) and NQO-1 (lower). Bars represent the mean \pm SD. ${ }^{*} P<0.05$ versus indicated groups. Scale bars $=50 \mu \mathrm{m}$ 


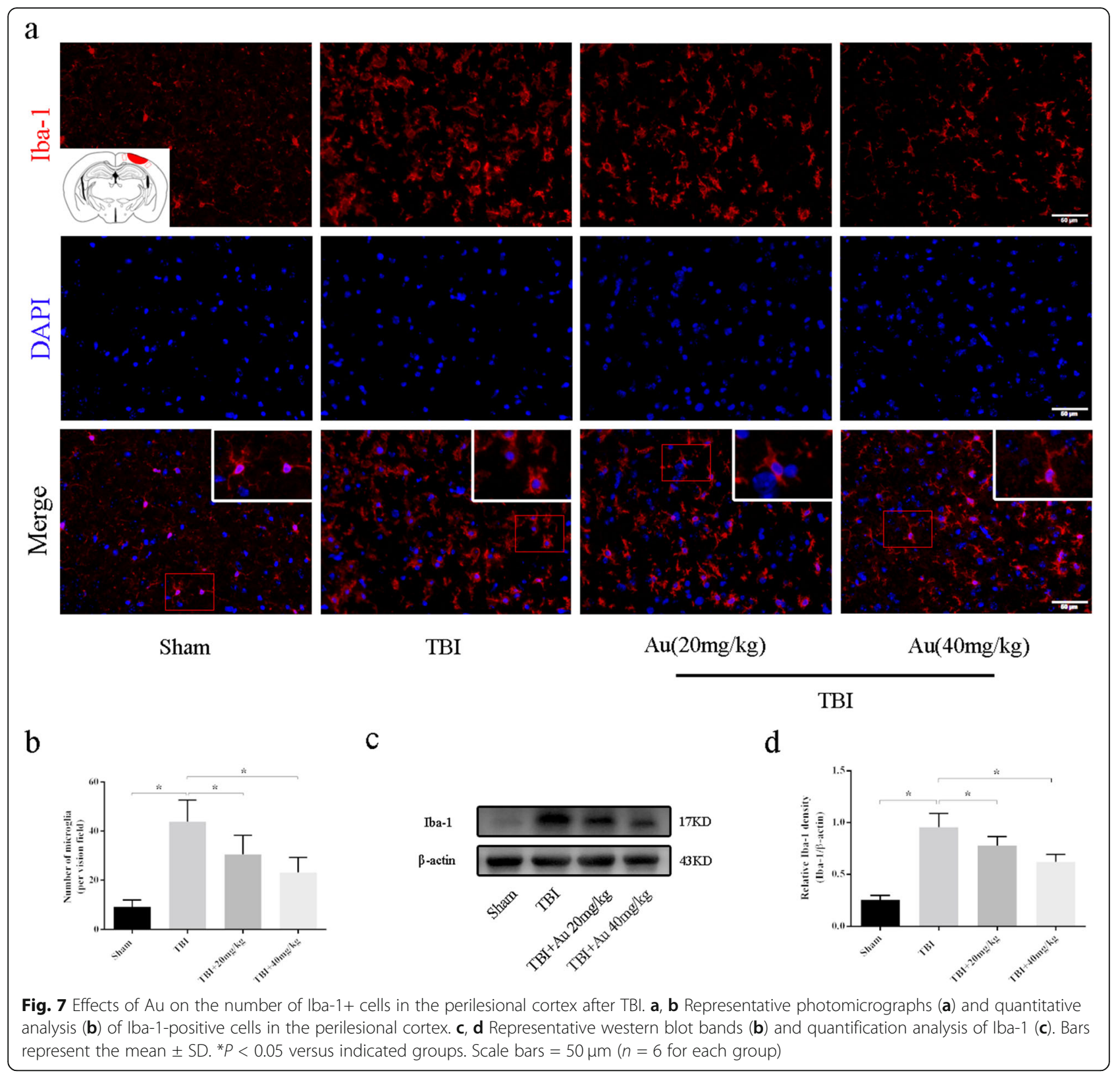

test the effect of Nrf2 interference, q-PCR and WB analyses were performed. The results showed that Nrf2 shRNA significantly depressed expression of Nrf2 at the mRNA and protein levels (Fig. 9a-c). We further evaluated protein levels of nuclear Nrf2. Au and Nrf2 shRNA co-treated mice displayed a reduction in nuclear Nrf2 compared with that of the TBI $+\mathrm{Au}+\mathrm{NC}$ group (Fig. 9d, f). Expression levels of HO-1 and Bcl2 were notably decreased in TBI + Au + LV groups, whereas Au-treated mice with Nrf2 interference showed increased protein expression of Bax and CC3 (Fig. 9d-f).

Finally, we measured expression of HMGB1-TLR4 pathway components. The results indicated that Nrf2 knockdown significantly increased expression levels of
HMGB1, TLR4, MyD88, nuclear NF-kB p65, and COX2 as compared with those of the TBI $+\mathrm{Au}+\mathrm{NC}$ group (Fig. 9g-i).

\section{Discussion}

Secondary brain injury has complex and varied pathophysiological mechanisms. Substantial evidence suggests that oxidative stress participates in secondary brain injury $[4,10,11,17]$. Recently, studies have demonstrated that $\mathrm{Au}$ has potent antioxidant effects and reduces excessive production of ROS in non-alcoholic fatty liver disease and acute lung injury $[37,38]$. Until now, few experiments investigated the potential antioxidative in CNS diseases, except that Xue and colleagues reported 


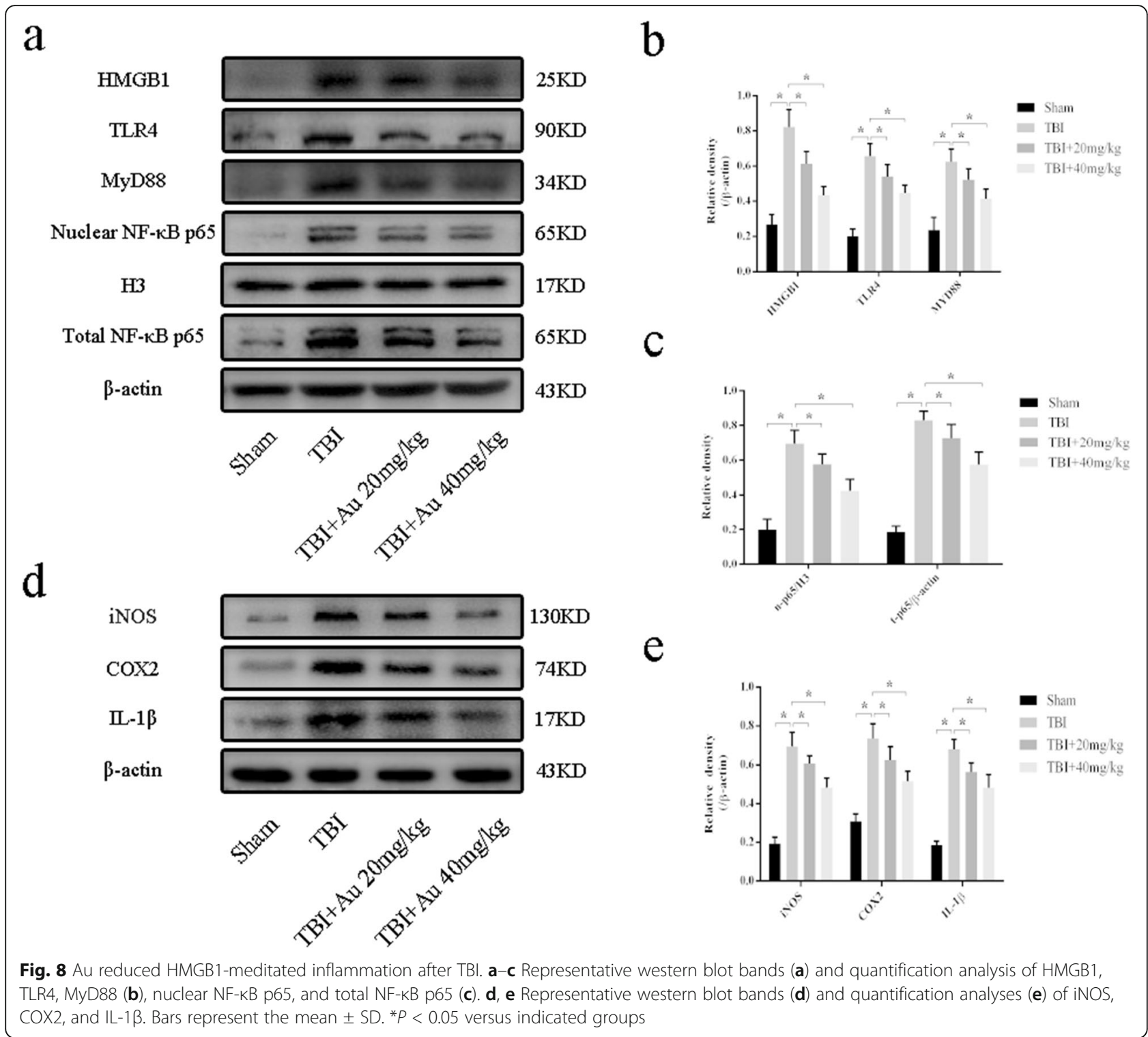

the antioxidant bioactivities of Au in P12 cells (a neuronal cell line) and in a rat model of diabetic encephalopathy [27-29]. In the present study, we first investigated the antioxidative effects of $\mathrm{Au}$ on primary neurons. We found that $\mathrm{Au}$ inhibited intercellular ROS generation, restored the balance between the expression of $\mathrm{Bcl} 2$ and Bax, and suppressed caspase- 3 activation. These results are consistent with those of previous studies [27, 37]. Then, we further tested the effectiveness of Au in TBI mice. We found that Au administration substantially reduced MDA content and numbers of 8-OHdG-positive cells, which are markers of oxidative stress and indicate the presence of cellular damage and destruction [39]. Concomitant with the decreased generation of ROS, $\mathrm{Au}$ also increased brain and serum levels of essential antioxidant enzymes that inhibit the overproduction of ROS.
These findings suggest that $\mathrm{Au}$ activates ARE to regulate cellular oxidant-antioxidant balance. TBI causes cerebral cortex damage that has been confirmed to affect a series of neurobehavioral functions [40]. In addition to motor deficits, TBI mice in our experiments exhibited cognitive impairments that were mitigated by Au treatment. This suggests that $\mathrm{Au}$ augments brain tissue repair and promotes functional recovery. Published literatures have shown that the neuroprotective effect of $\mathrm{Au}$ was both in the short term and the long term. The mechanisms involve in oxidative stress-induced neuronal loss [41]. After Au treatment, attenuation of oxidative stress could reduce neuronal loss in hippocampus [27-29]. Similarly, we found that Au decreased the loss of neurons both in cortex and hippocampus in a mouse TBI model. We hypothesized that the improvement of 


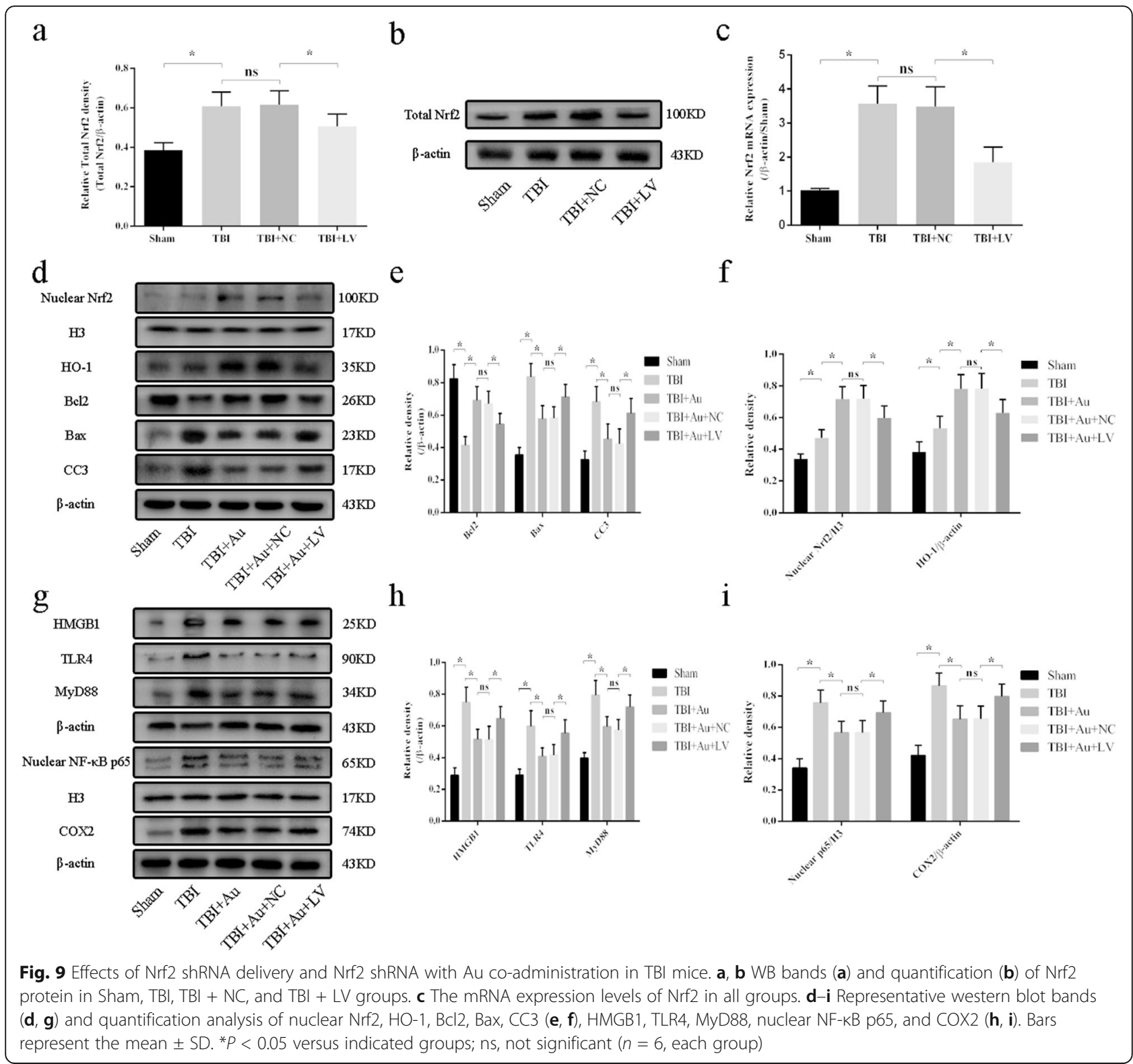

neurologic functions in TBI mice was probably due to the fact that $\mathrm{Au}$ alleviated oxidative stress.

Nrf2 plays an indispensable role in maintaining cellular homeostasis. Substantial lines of evidence have suggested that it is beneficial for CNS diseases, including TBI [13-15]. Under physiologic conditions, Nrf2 binds with Keap1 in the cytoplasm. However, under conditions of injury, Nrf2 dissociates from Keap1 and translocates into the nucleus, where it activates the Nrf2-ARE pathway. Au has been demonstrated to have the property to promote Nrf2 into nuclear, which triggers Nrf2-induced antioxidative signaling pathway $[31,32]$. In both in vitro and in vivo studies, we did find that $\mathrm{Au}$ enhanced nuclear accumulation of Nrf2 and increased cytoplasmic expression of HO-1 and NQO1 in neurons. While Nrf2 was downregulated, the antiapoptotic and antioxidative properties were abrogated. These results indicate that $\mathrm{Au}$ ameliorated TBI in an Nrf2-dependent manner.

Inflammation is one of the major determinants of secondary brain damage after TBI [5]. Activated microglia, the principle resident macrophages of the CNS, produce and release a number of proinflammatory cytokines and chemokines. These cytokines activate and recruit more inflammatory cells to amplify the inflammatory response [42]. Au restrains the activation of astrocytes and microglia [26, 30]. Our results showed that $\mathrm{Au}$ inhibited the activation of microglia and prevented them from accumulating 
in the injury cortex. Moreover, we observed that $\mathrm{Au}$ markedly reduced protein levels of inflammatory cytokines. These findings suggest that $\mathrm{Au}$ also provides neuroprotective effects in a TBI model via antiinflammation, whereas the anti-inflammatory role of $\mathrm{Au}$ was abrogated by Nrf2 knockdown. Consistent with these results, a recent study has shown that Nrf2 knockdown in RAW267.4 cells diminished the bioactivity of $\mathrm{Au}$ to impede inflammation, indicating that Au-inhibited inflammation dependents on Nrf2 expression [32].

In TBI, there is crosstalk between oxidative and inflammation. ROS deplete cellular antioxidants, react with nucleotides and proteins, and induce peroxidation of cellular membranes, further damaging cells and organelles, which initiates or intensifies inflammation [6, 8]. Damaged neurons and activated microglia passively and actively release HMGB1 into the extracellular milieu, respectively $[20,21]$. HMGB1 binds with TLR4, a member of the TLR family, initiating the MyD88-dependent pathway leading to direct NF- $\mathrm{KB}$ activation and inducing the production of proinflammatory genes and chemokines [22-24]. A study has reported reduced expression of HMGB1 caused by $\mathrm{Au}$ treatment in epileptic mice [30]; however, the mechanism remains unclear. In the TBI model, our studies showed that Au inhibited HMGB1-TLR4 signaling pathway-mediated neuroinflammation, but this process relies on the expression of Nrf2. We hypothesize that attenuation of oxidative stress reduces the release of HMGB1, which alleviates the inflammatory response. Similarly, Zeng and Wang have reported that elevated antioxidant response reduces the inflammation and weakens the brain damage in the TBI model $[10,12]$.

There are several potential limitations deserving attention in our experiments. First, although studies have shown that Au plays a protective role by phosphorylating AMPK to regulate Nrf2 translocation into the nucleus [31, 32], we did not explore the specific molecular mechanism in TBI mice. Second, we only used Nrf2 shRNA to explore the mechanism, which might not have had an efficient inhibitor effect. Therefore, the data from Nrf2 knockout mice might be more persuasive.

\section{Conclusions}

In summary, we provide evidence that Au has antioxidative and anti-inflammatory bioactivities in a TBI model. The underlying molecular mechanisms of these beneficial effects involve in regulation of ROS and HMGB1-mediated inflammation by trigger Nrf2ARE signaling pathway. Our experimental results might provide a novel therapeutic strategy for TBI.

\section{Supplementary information}

Supplementary information accompanies this paper at https://doi.org/10. 1186/s12974-020-01863-9.

Additional file 1: Supplemental Figure 1: Representative image of the cortical lesion caused by a weight-drop system. Shaded areas illustrate the perilesional cortex that was harvested for WB, ELISA and q-PCR analysis. Supplemental Figure 2: Modified Neurological Severity Score points. 1 score is awarded for the inability to perform the test or for the lack of a tested reflex (normal score, 0; maximal score, 18). Supplemental Figure 3: Au alleviated the neural apoptosis and neuronal loss in hippocampus. (a, c) Representative photomicrographs and quantification of Nissl staining in the CA1 region of hippocampus (scale bars $=20 \mu \mathrm{m})$. (b, d) Representative photomicrographs and quantification of TUNEL staining in the CA1 region of hippocampus. Red, TUNEL; blue, DAPI (scale bars $=50 \mu \mathrm{m}$ ). (e) Diagram of mouse brain section showing the location of lesion cavity (red) and photograph region (red square). Bars represent the mean \pm SD. ( $n=6$ for each group, one-way ANOVA, ${ }^{*} P<0.05$ versus indicated groups). Supplemental Figure 4: Quantification of Nrf2 fluorescent intensity (oneway ANOVA, ${ }^{*} P<0.05$ versus indicated groups).

\section{Abbreviations}

Au: Aucubin; TBI: Traumatic brain injury; TUNEL: TdT-mediated dUTP Nick-End Labeling; q-PCR: Quantitative real time polymerase chain reaction;

ELISA: Enzyme linked immunosorbent assay; Nrf2: Nuclear factor erythroid-2 related factor 2; ROS: Reactive oxygen species; HMGB1: High mobility group box 1; DAMPs: Damage associated molecular patterns; CNS: Central nervous system; Keap 1: Kelch-like ECH-associated protein 1; HO-1: Heme oxygenase-1; NQO-1: NAD(P)H: quinone oxidoreductase-1; GPX: Glutathione peroxidase; GST: Glutathione-S-transferase; SOD: Superoxide dismutase; TLRs: Toll-like receptors; NF-KB: Nuclear factor-KB; MyD88: Myeloid differentiation factor 88; mNSS: Modified Neurological Severity Scores; MWM: Morris Water Maze; BWC: Brain water content; WB: Western blot; IF: Immunofluorescence; IHC: Immunohistochemistry; NC: Negative control; LV: Lentiviral vectors; Bcl2: B-cell lymphoma-2; Bax: Bcl-2 Associated X Protein; CC3: Cleavedcaspase 3; COX2: Cyclooxygenase-2; iNOS: Inducible Nitric Oxide Synthase; IL$1 \beta$ : Interleukin-1 $\beta$; ECL: Enhanced chemiluminescence; DCFH-DA: M29,79dichlorodihydrofluorescein diacetate; 8-OHdG: 8-Hydroxyguanosine; ICV: Intracerebroventricular

\section{Acknowledgements}

Not applicable

\section{Authors' contributions}

Hang CH and Li W contributed to the design and analysis of the study and revised the manuscript; Wang $H$ was responsible for performing experiments and manuscript drafting; Zhou XM and Wu LY participated in creating the experimental animal model, drug administration, and lentivirus injection; Liu GJ and Xu WD were responsible for WB and cell culture; Zhang XS and Gao YY were responsible for neurological evaluation and q-PCR; Tao T was responsible for IF staining and IHC staining; Zhou $Y$ was responsible for ELISA and ROS detection; Lu Y was responsible for Nissl staining; Wang J was responsible for TUNEL staining; Deng CL was responsible for data collection; Zhuang Z was responsible for data analysis. All authors read and approved the final manuscript

\section{Funding}

This work was funded by National Natural Science Foundation of China (NSFC) (No.81870922, No.81801166, No.81771291, No.81901203, No.81971127), the China Scholarship Fund (No.201606190196), the Fundamental Research Funds for the Central Universities (No.021414380361), and Medical Science and Technology Development Foundation, Nanjing Department of Health (No.JQX18001).

\section{Availability of data and materials}

All data during this study are included in this article.

Ethics approval and consent to participate

This study was approved by the Ethics Review Committee of Drum Tower Hospital. 


\section{Consent for publication}

Not applicable

\section{Competing interests}

The authors have no conflict of interest to disclose.

\section{Author details}

'Department of Neurosurgery, Nanjing Drum Tower Hospital, The Affiliated Hospital of Nanjing University Medical School, 321\# Zhongshan Road, Nanjing 210008, China. ²Department of Neurosurgery, Jinling Hospital, School of Medicine, Nanjing University, Nanjing, China. ${ }^{3}$ Department of Neurosurgery, Jinling Hospital, School of Medicine, Nanjing University, Nanjing, China.

\section{Received: 19 February 2020 Accepted: 2 June 2020} Published online: 15 June 2020

\section{References}

1. Lingsma HFM, Roozenbeek BM, Steyerberg EWP, Murray GDP, Maas AIM Early prognosis in traumatic brain injury: from prophecies to predictions. Lancet Neurology, The. 2010;9:543-54.

2. Kuo C, Liou T, Chang K, Chi W, Escorpizo R, Yen C, Liao H, Chiou H, Chiu W, Tsai J. Functioning and disability analysis of patients with traumatic brain injury and spinal cord injury by using the world health organization disability assessment schedule 2.0. Int J Env Res Public He. 2015;12:4116-27.

3. Sande A, West C. Traumatic brain injury: a review of pathophysiology and management. J Vet Emerg Crit Car. 2010;20:177-90.

4. Cornelius C, Crupi R, Calabrese V, Graziano A, Milone P, Pennisi G, Radak Z, Calabrese EJ, Cuzzocrea S. Traumatic brain injury: oxidative stress and neuroprotection. Antioxid Redox Signal. 2013;19:836-53.

5. Simon DW, McGeachy MJ, Bayir H, Clark R, Loane DJ, Kochanek PM. The farreaching scope of neuroinflammation after traumatic brain injury. Nat Rev Neurol. 2017;13:171-91

6. Sivandzade F, Prasad S, Bhalerao A, Cucullo L. NRF2 and NF-B interplay in cerebrovascular and neurodegenerative disorders: molecular mechanisms and possible therapeutic approaches. Redox Biol. 2019;21: 101059.

7. Hall ED, Vaishnav RA, Mustafa AG. Antioxidant therapies for traumatic brain injury. Neurotherapeutics. 2010;7:51-61.

8. Eastman CL, D'Ambrosio R, Ganesh T. Modulating neuroinflammation and oxidative stress to prevent epilepsy and improve outcomes after traumatic brain injury. Neuropharmacology. 2019;107907.

9. Forrester SJ, Kikuchi DS, Hernandes MS, Xu Q, Griendling KK. Reactive oxygen species in metabolic and inflammatory signaling. Circ Res. 2018;122: 877-902.

10. Wang J, Jiang C, Zhang K, Lan X, Chen X, Zang W, Wang Z, Guan F, Zhu C, Yang $X$, et al. Melatonin receptor activation provides cerebral protection after traumatic brain injury by mitigating oxidative stress and inflammation via the Nrf2 signaling pathway. Free Radic Biol Med. 2019:131:345-55.

11. Fang J, Wang H, Zhou J, Dai W, Zhu Y, Zhou Y, Wang X, Zhou M. Baicalin provides neuroprotection in traumatic brain injury mice model through Akt/Nrf2 pathway. Drug Des Devel Ther. 2018;12:2497-508.

12. Zeng J, Chen $Y$, Ding R, Feng $L$, Fu Z, Yang S, Deng $X$, Xie Z, Zheng $S$. Isoliquiritigenin alleviates early brain injury after experimental intracerebral hemorrhage via suppressing ROS- and/or NF-kB-mediated NLRP3 inflammasome activation by promoting Nrf2 antioxidant pathway. $J$ Neuroinflammation. 2017;14.

13. Liu L, Locascio LM, Dore S. Critical role of Nrf2 in experimental ischemic stroke. Front Pharmacol. 2019;10:153.

14. Calkins MJ, Johnson DA, Townsend JA, Vargas MR, Dowell JA, Williamson TP, Kraft AD, Lee JM, Li J, Johnson JA. The Nrf2/ARE pathway as a potential therapeutic target in neurodegenerative disease. Antioxid Redox Signal. 2009; 11:497-508.

15. Zhang L, Wang H. Targeting the NF-E2-related factor 2 pathway: a novel strategy for traumatic brain injury. Mol Neurobiol. 2018:55:1773-85.

16. Lv H, Liu Q, Zhou J, Tan G, Deng X, Ci X. Daphnetin-mediated Nrf2 antioxidant signaling pathways ameliorate tert-butyl hydroperoxide (t-BHP)-induced mitochondrial dysfunction and cell death. Free Radic Biol Med. 2017;106:38-52.

17. Ding $K$, Wang $H$, Xu J, Li T, Zhang L, Ding Y, Zhu L, He J, Zhou M. Melatonin stimulates antioxidant enzymes and reduces oxidative stress in experimental traumatic brain injury: the Nrf2-ARE signaling pathway as a potential mechanism. Free Radic Biol Med. 2014:73:1-11.

18. Wang J, Fields J, Zhao C, Langer J, Thimmulappa PK, Kensler TW, Yamamoto M, Biswal S, Dore S. Role of Nrf2 in protection against intracerebral hemorrhage injury in mice. Free Radic Biol Med. 2007;43:408-14.

19. Paudel YN, Shaikh MF, Chakraborti A, Kumari Y, Aledo-Serrano A, Aleksovska K, Alvim M, Othman I. HMGB1: a common biomarker and potential target for TBI, neuroinflammation, epilepsy, and cognitive dysfunction. Front Neurosci. 2018;12

20. Yamada S, Maruyama I. HMGB1, a novel inflammatory cytokine. Clin Chim Acta. 2007:375:36-42.

21. Gao T-L, Yuan X-T, Yang D, Dai H, Wang WJ, Peng X, Shao HJ, Jin ZF, Fu ZJ. Expression of HMGB1 and RAGE in rat and human brains after traumatic brain injury. J Trauma Acute Care Surg. 2012;72:643-9.

22. Miyake K. Innate immune sensing of pathogens and danger signals by cell surface Toll-like receptors. Semin in Immunol. 2007;19:3-10.

23. Yang Y, Lv J, Jiang S, Ma Z, Wang D, Hu W, Deng C, Fan C, Di S, Sun Y, Yi W. The emerging role of Toll-like receptor 4 in myocardial inflammation. Cell Death Dis. 2016:7:e2234-4

24. Lu Y, Zhang XS, Zhang ZH, Zhou XM, Gao YY, Liu GJ, Wang H, Wu LY, Li W, Hang $\mathrm{CH}$. Peroxiredoxin 2 activates microglia by interacting with Toll-like receptor 4 after subarachnoid hemorrhage. $J$ Neuroinflammation. 2018;15:87.

25. Zeng X, Guo F, Ouyang D. A review of the pharmacology and toxicology of aucubin. Fitoterapia. 2020;140:104443.

26. Zhu Y, Sun $M$, Jia $X$, Zhang $P$, Xu Y, Zhou Z, Xu Z, Cui C, Chen X, Yang $X$, Shen $Y$. Aucubin alleviates glial cell activation and preserves dopaminergic neurons in 1-methyl-4-phenyl-1,2,3,6-tetrahydropyridineinduced parkinsonian mice. NeuroReport. 2018;29:1075-83.

27. Xue HY, Jin L, Jin L, Li XY, Zhang P, Ma YS, Lu YN, Xia YQ, Xu YP. Aucubin prevents loss of hippocampal neurons and regulates antioxidative activity in diabetic encephalopathy rats. Phytother Res. 2009:23:980-6.

28. Xue HY, Lu YN, Fang XM, Xu YP, Gao GZ, Jin LJ. Neuroprotective properties of aucubin in diabetic rats and diabetic encephalopathy rats. Mol Biol Rep. 2012;39:9311-8

29. Xue $H$, Jin $L$, Jin L, Zhang $P$, Li D, Xia Y, Lu Y, Xu Y. Neuroprotection of aucubin in primary diabetic encephalopathy. Science in China Series C: Life Sciences. 2008:51:495-502.

30. Chen S, Zeng X, Zong W, Wang X, Chen L, Zhou L, Li C, Huang Q, Huang $X$, Zeng $G$, et al. Aucubin alleviates seizures activity in LiPilocarpine-Induced epileptic mice: involvement of inhibition of neuroinflammation and regulation of neurotransmission. Neurochem Res. 2019:44:472-84

31. Shen B, Zhao C, Wang Y, Peng Y, Cheng J, Li Z, Wu L, Jin M, Feng H. Aucubin inhibited lipid accumulation and oxidative stress via $\mathrm{Nrf2} / \mathrm{HO}-1$ and AMPK signalling pathways. J Cell Mol Med. 2019;23:4063-75.

32. Qiu YL, Cheng XN, Bai F, Fang LY, Hu HZ, Sun DQ. Aucubin protects against lipopolysaccharide-induced acute pulmonary injury through regulating Nrf2 and AMPK pathways. Biomed Pharmacother. 2018:106:192-9.

33. Singhal A, Morris VB, Labhasetwar V, Ghorpade A. Nanoparticle-mediated catalase delivery protects human neurons from oxidative stress. Cell Death Dis. 2013;4:e903

34. Zhang X, Wu Q, Lu Y, Wan J, Dai H, Zhou X, Lv S, Chen X, Zhang X, Hang C, Wang J. Cerebroprotection by salvianolic acid B after experimental subarachnoid hemorrhage occurs via Nrf2- and SIRT1-dependent pathways. Free Radical Biol Med. 2018;124:504-16.

35. Lu C, Xu W, Shao J, Zhang F, Chen A, Zheng S. Nrf2 activation is required for ligustrazine to inhibit hepatic steatosis in alcohol-preferring mice and hepatocytes. Toxicol Sci. 2017;155:432-43.

36. Wang H, Zhou XM, Xu WD, Tao T, Liu GJ, Gao YY, Lu Y, Wu LY, Yu Z, Yuan B, et al. Inhibition of elevated hippocampal CD24 reduces neurogenesis in mice with traumatic brain injury. J Surg Res. 2020;245:321-9.

37. Xue HY, Niu DY, Gao GZ, Lin QY, Jin LJ, Xu YP. Aucubin modulates BCl-2 family proteins expression and inhibits caspases cascade in $\mathrm{H}_{2} \mathrm{O}_{2}$-induced PC12 cells. Mol Biol Rep. 2011;38:3561-7.

38. Xue HY, Gao GZ, Lin QY, Jin LJ, Xu YP. Protective effects of aucubin on $\mathrm{H}(2) \mathrm{O}(2)$-induced apoptosis in PC12 cells. Phytother Res. 2012;26: 369-74.

39. Li Q, Han X, Lan X, Gao Y, Wan J, Durham F, Cheng T, Yang J, Wang Z, Jiang $C$, et al. Inhibition of neuronal ferroptosis protects hemorrhagic brain. JCI Insight. 2017;2:e90777. 
40. Kragel PA, Kano M, Van Oudenhove L, Ly HG, Dupont P, Rubio A, DelonMartin C, Bonaz BL, Manuck SB, Gianaros PJ, et al. Generalizable

representations of pain, cognitive control, and negative emotion in medial frontal cortex. Nat Neurosci. 2018:21:283-9.

41. Zhao B. Natural antioxidants for neurodegenerative diseases. Mol Neurobiol. 2005;31:283-93.

42. Jassam YN, Izzy S, Whalen M, McrGavem DB. E1KJ: Neuroimmunology of traumatic brain injury: time for a paradigm shift. Neuron. 2017;95:1246-65.

\section{Publisher's Note}

Springer Nature remains neutral with regard to jurisdictional claims in published maps and institutional affiliations.

Ready to submit your research? Choose BMC and benefit from:

- fast, convenient online submission

- thorough peer review by experienced researchers in your field

- rapid publication on acceptance

- support for research data, including large and complex data types

- gold Open Access which fosters wider collaboration and increased citations

- maximum visibility for your research: over $100 \mathrm{M}$ website views per year

At $\mathrm{BMC}$, research is always in progress.

Learn more biomedcentral.com/submissions 